University of Windsor

Scholarship at UWindsor

Mechanical, Automotive \& Materials

Department of Mechanical, Automotive \& Engineering Publications Materials Engineering

Winter 2-19-2018

\title{
Dual-Channel Warehouse and Inventory Management with Stochastic Demand
}

Fawzat Alawneh

Guoqing Zhang

Follow this and additional works at: https://scholar.uwindsor.ca/mechanicalengpub

Part of the Business Administration, Management, and Operations Commons, Business Analytics Commons, E-Commerce Commons, Industrial Engineering Commons, and the Operational Research Commons

\section{Recommended Citation}

Alawneh, Fawzat and Zhang, Guoqing. (2018). Dual-Channel Warehouse and Inventory Management with Stochastic Demand. Dual-Channel Warehouse and Inventory Management with Stochastic Demand, 112, 84-106.

https://scholar.uwindsor.ca/mechanicalengpub/9

This Article is brought to you for free and open access by the Department of Mechanical, Automotive \& Materials Engineering at Scholarship at UWindsor. It has been accepted for inclusion in Mechanical, Automotive \& Materials Engineering Publications by an authorized administrator of Scholarship at UWindsor. For more information, please contact scholarship@uwindsor.ca. 


\title{
Dual-channel Warehouse and Inventory Management with Stochastic Demand
}

\author{
Fawzat Alawneh and Guoqing Zhang* \\ Supply Chain and Logistics Optimization Research Centre, Department of Mechanical, \\ Automotive \& Materials Engineering, University of Windsor, Windsor, Ontario, Canada \\ *Corresponding author. Email: gzhang@uwindsor.ca
}

\begin{abstract}
This study examines the inventory policy for the emerging dual-channel warehouse, which has a unique structure where the warehouse is divided into two areas: one for fulfilling online orders and the other for storing products and fulfilling offline orders. A multi-item inventory model was developed considering the warehouse capacity constraint, demand, and lead time uncertainty. Solution methods are provided for both uniform and normal distributions. Adopting the proposed inventory policy for a dual warehouse is cost effective and adds flexibility to the warehouse and supply chain. The study also offers managerial insights on some critical issues faced by companies operating in a dual-channel context.
\end{abstract}

Keywords: dual-channel warehouse; online fulfillment; inventory; uncertainty

\section{Introduction}

Online sales have experienced a significant growth in recent years (Wu, 2015). The total ecommerce sales in the United States reached $\$ 341.8$ billion in 2015 , which is a $14.8 \%$ increase from 2014 (U.S. Department of Commerce). It is believed that this increase was because many firms upgraded their single-channel, offline sales business models to dual-channel clicks-andmortar models, which integrate both online and offline sales, during that time. Moreover, it has been predicted that such growth in online sales will continue: web-influenced sales are expected to grow annually by 6\% between 2015 and 2020 (Wu, 2015). Studies have shown that in 2008, 94\% of the best financially performing firms were dual-channel sales firms (Kilcourse and Rowen, 2008). The emergence of dual-channel firms was mainly driven by the expansion in internet use 
and the advances in information and manufacturing technologies providing competitive advantage to the supply chain (Gunasekaran et al., 2017).

Firms introducing online sales are facing many challenges in terms of logistics and delivery processes, such as large volumes of very small orders, short delivery lead times, flexible delivery (for example, nighttime and even 24-h shipping), and the picking and packing process for single unit orders, in addition to the usual challenges of the conventional business. Warehouses or distribution centers must be ready to prepare orders coming from both offline stores and online shoppers. The conventional warehouse designed for physical stores and delivery does not work under a dual-channel business environment. For example, warehouse workers cannot use the same picking patterns for online orders as for physical shoppers (Master, 2015). Warehouses operating in the current digital era of e-commerce must have the all-purpose infrastructure, which is capable of sharing information, being interconnected, and handling different orders from different customer segments with different features such as diverse order sizes and delivery lead times (McCrea, 2017; Graves, 2012).

Two common strategies for warehouses or fulfillment process in the dual-channel business environment are the decentralized and centralized policies. A firm with a decentralized warehouse policy establishes a dedicated e-fulfillment warehouse and has separate warehouses where each sales channel has separate inventory, operation, and commercial teams. In many situations, using a decentralized policy for all channels in dual-channel strategies results in inefficiency (Bendoly, 2004; Zhang et al., 2010; Hübner et al., 2015). Despite the current profits of these firms, they lack inter-channel coordination, which leads to long-term inefficiency and consumer confusion (Zhang et al., 2010).

The strategy of using a centralized warehouse, i.e., one integrated warehouse or several warehouses clustered in the same location, to serve both online and offline orders for a region has recently gained popularity and is the most common organizational structure for dual-channel markets (Agatz et al., 2008; Hübner et al., 2015; Hübner et al., 2016). The strategy's growth in popularity is owing to the advantages that have been perceived by the firms adopting it. Such firms include the International Business Machines Corporation, Hewlett-Packard, Whirlpool Corporation, Pioneer Corporation, Hamilton Beach, and Nike (Huang et al., 2012; Zhang and Tian, 2014; Li et al., 2015; Panda et al., 2015; Xiao and Shi, 2016). The advantages of this structure include reducing the facility cost by building an integrated warehouse, reducing warehouse space 
and inventory required for both channels, increasing the coordinating ability and flexibility of fulfilling both online and offline orders, and increasing the service levels.

One of the challenges in running the dual-channel warehouse is how to organize the warehouse and manage inventory to fulfill both online and offline (retailer) orders, where the orders from different channels have different features. Two important differences are the order size and order time. Typical online orders are placed at random times and are usually of small sizes, while typical offline orders are placed at scheduled times and are usually of large sizes (Agatz et al., 2008). Those differences affect the warehouse structure and operation. Many firms with dual-channel distribution systems have difficulty on developing an effective inventory policy to reach an optimal channel performance. One of the key issues they face is deciding on the optimal order quantity and reorder point when a new sales channel is introduced. Moreover, they need to consider both capacity constraints and uncertain demands (of both offline and online channels).

New streams of research have recently commenced studying dual-channel supply chains. One stream has focused on the competition and coordination that arise between sales channels (Hua and Li, 2008; Lu and Liu, 2015; Lin, 2016; Matsui, 2016; Wang et al., 2016; Chen and Chen, 2017). Another stream has studied the challenging logistics and processes of fulfilling online orders once they have been placed (De Koster, 2003; Tetteh and Xu, 2014). Research has also been centered on price and service interaction between channels (Yao and Liu, 2005; Ryan et al., 2013; Panda et al., 2015; Rodríguez and Aydin, 2015; Liu et al., 2016; Xiao and Shi, 2016; Yan et al., 2016; Giri et al., 2017; Matsui, 2017), and online order fulfillment processes (Agatz et al., 2008; Mahar et al., 2009). Inventory management in dual-channel supply chains has also been explored (Khouja, 2003; Yao et al., 2009; Zhang and Tian, 2014; Zhao et al., 2016). However, none of the emerging research streams has examined inventory management in a joint warehouse while considering the operations and capacity of the warehouse.

Therefore, this study examines the inventory policies for joint warehouse or distribution systems, called dual-channel warehouse in dual-channel business. As an important part of logistics, the warehouse plays a critical role in fulfilling the demands from both channels. The dual-channel warehouse has a unique structure: the warehouse is separated into two areas, one for fulfilling online orders and the other for storing products and fulfilling offline orders, as shown in Figure 1(c) (The details will be explained in Section 3). A warehouse with such a structure is utilized by retailers, manufacturers, or third-party logistics (3PLs), who use a centralized warehouse for 
fulfilling both online and offline orders. We also have observed a couple of dual-channel warehouses of retailers or 3PLs in both China and Canada. A similar structure can be found in ecommerce firms that only have online customers (Xu, 2005), as shown in Figure 1(b).

Figure 1 shows the difference between a dual-channel warehouse and a conventional retailer warehouse or an e-commerce warehouse. As shown, the dual-channel warehouse has two areas that fulfill the online and retailer orders. The focus of our study is to analyze the structure of the dual-channel warehouse and determine multi-item inventory policy $(\mathrm{Q}, \mathrm{R})$ for both areas, taking into account the warehouse capacity, demand, and lead time uncertainty so that the total cost of the dual-channel warehouse would be minimized.

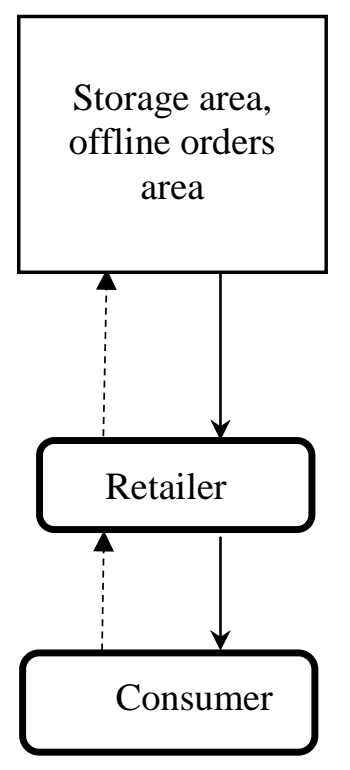

(a)

$\longrightarrow$ Product flow

Information flow

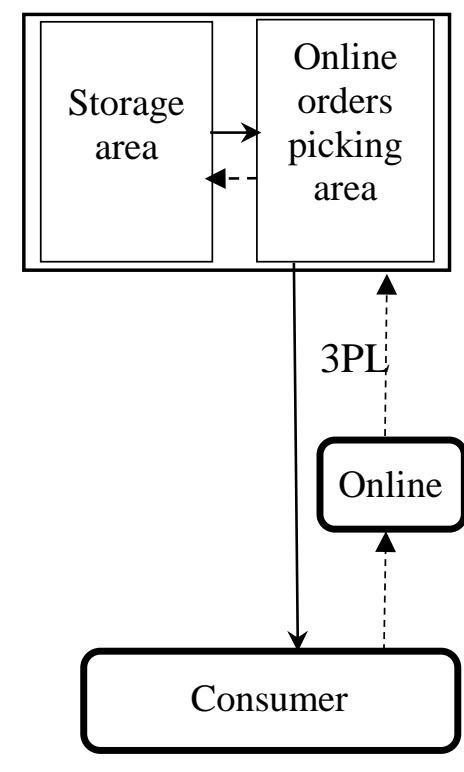

(b)

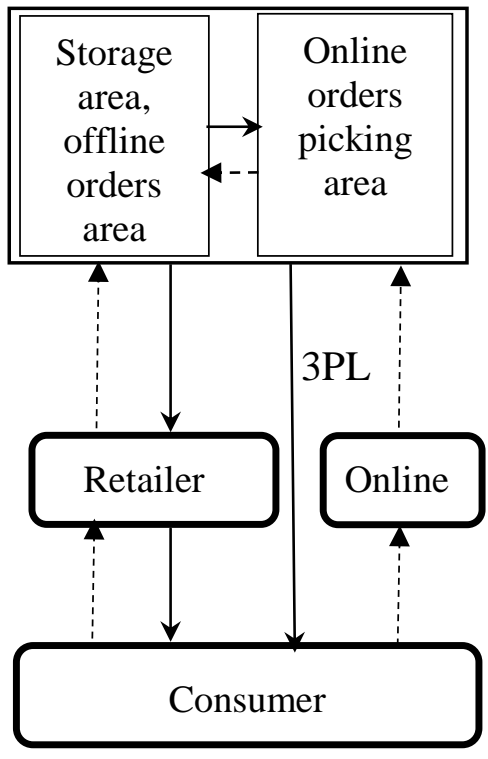

(c)

Figure 1. (a)-(b) Single-channel warehouses and (c) dual-channel warehouse

Designing a suitable warehouse structure for a centralized warehouse policy is critical for warehouse operations to prepare orders from both online and offline shoppers. Logistics viewpoint indicate that it is common to find modern warehouse layouts divided into different areas for each customer platform (Master, 2015). One of the best warehouse practices for 2017 is to develop allpurpose facilities that can "talk" to one another, handle small orders, medium orders, and large 
orders, and perform all functions in a very accurate manner (McCrea, 2017). A dual-channel warehouse that introduces a new area for e-fulfillment process provides an efficient and practical structure to connect two warehouse areas for centralized warehouse policy. Usually, for heavy or bulky items such as refrigerators and large furniture, a dedicated e-fulfillment warehouse is a better choice because it has a low-cost efficiency in moving those items frequently in different areas of a warehouse. For most items in electronics, department stores, and even grocery stores, a dualchannel warehouse can be a good option because the added dedicated e-fulfillment area can be designed to provide an efficient and flexible solution for high volume of small orders, such as lowdensity warehouse, low inventory, special equipment or structure, and long operation time. Two dual-channel warehouses observed in China and Canada are used for electronic products and grocery store items respectively.

This study contributes to the existing literature on warehouse management in several ways. First, it is the first work to analyze the structure of the emerging dual-channel warehouses and develop a structure related to the inventory policy for such warehouses. Second, it develops a mathematical model that determines the multi-item product inventory policy for the two areas in integrated dual-channel warehouses, minimizing their total expected cost. The constraints of warehouse space and uncertain demands are also considered. Third, it provides closed-form solutions for instances without a warehouse space constraint as well as a solution algorithm for the case with the warehouse space constraint. Furthermore, the proposed solution can be used to evaluate the performance of two-echelon dual-channel warehouse systems by comparing the total system costs for different warehouse structures and evaluating the effects of adding a new sales channel. To the best of our knowledge, this study is the first work to address the inventory policies of the emerging dual-channel warehouses with a unique structure, although, there have been several studies on inventory policies of a dual-channel supply chain.

The rest of this paper is divided into six sections. Section 2 provides a comprehensive literature review of inventory management and dual-channel warehouses in a dual-channel supply chain. Section 3 provides the aforementioned mathematical model. Next, approaches to the solution are presented in Section 4. An extension to correlated demands is discussed in Section 5, while the numerical results and analysis are presented in Section 6. Finally, Section 7 summarizes the conclusions and discusses potential and relevant future research. 


\section{Literature review}

This study is related to two streams of literature that have examined dual-channel supply chains: inventory management in dual-channel supply chains and warehouse operations, layout designs, and capacity management in dual-channel warehouses. A literature review of each of these topics can be found below.

\section{Inventory management in dual-channel supply chains}

Various forms of inventory management have been studied in the dual-channel supply chain literature. Chiang and Monahan (2005) proposed what may be described as one of the first models that studied inventory policy in a two-echelon dual-channel supply chain that receives demands from different customer segments. They assumed that the inventory was stored in both the manufacturer's warehouse to satisfy online demand and in retail stores to satisfy offline demand. They developed a stock-based inventory control strategy to minimize the system's operating cost by considering the inventory holding and lost sales costs. The model developed by Teimoury et al. (2008) is considered an extension to that by Chiang and Monahan (2005). The former's main contributions include the separation of both channels' lost sale costs and the development of two solution algorithms. One algorithm was based on the simulated annealing method, and the other algorithm was based on the best neighborhood concept. Takahashi et al. (2011) considered setup costs for both order production and order delivery. They proposed an inventory control strategy with the objective of minimizing inventory holding costs, lost sales costs, as well as production and delivery costs. They calculated the total cost using Markov analysis to highlight the performance of their proposed inventory control policy.

Boyaci (2005) also furthered research on dual-channel supply chains inventory management when he investigated the inventory levels of a retailer and a manufacturer with doublemarginalization. The author found that as double marginalization increased, the manufacturer tended to overstock while the retailer tended to be out of stock. Additionally, Geng and Mallik (2007) studied inventory competition between a direct online channel owned by a manufacturer and an offline retail channel. They claimed that the profit of a dual-channel supply chain would increase as the capacity increases. Furthermore, Hoseininia et al. (2013) investigated the competition that arose between channels; they based their system on a Stackelberg game. They analyzed the inventory level and its relationship to production costs and wholesale prices. 
Moreover, Schneider and Klabjan (2013) studied dual-channel revenue management by analyzing the conditions and effects of offering channel-specific prices. They also inspected the necessary conditions for optimal inventory control policies of dual-channel sales with channel-dependent sale prices.

Swaminathan and Tayur (2003) described the major adjustments necessary for a conventional supply chain to cope with e-commerce fulfillment processes. After a comprehensive literature review, they concluded that channel integration in a dual-channel supply chain increases profit, reduces inventory, and enhances customer service. However, the models studied in their paper primarily focused on electronic commerce. Hence, dual-channel operations and their interdependencies have not been discussed. Another significant review of supply chain management in an electronic commerce environment was conducted by Agatz et al. (2008). They focused on the distribution network design, warehouse layout, inventory, and capacity management topics. The authors divided the dual-channel fulfillment process into integrated fulfillment (using one warehouse to fulfill the demand of different sales channels) and dedicated fulfillment (using a dedicated warehouse for different channels). This division was based on their literature survey. Integrated fulfillment is the most common network among dual-channel firms.

Zhao et al. (2016) suggested a new inventory strategy called online-to-offline strategy. They considered a dual-channel supply chain with one manufacturer and one retailer. They also proposed a centralized and decentralized inventory model with and without lateral transshipment. The decision variables in their model were the inventory level for the store and transshipment price; however, no ordering or holding costs were considered. They demonstrated the existence of a unique Nash equilibrium of the inventory order levels in the dual channel and an optimal transshipment price to maximize the profit of the entire supply chain. However, they neither considered the dual-channel warehouse nor the ordering and holding costs. Zhang and Tian (2014) studied a dual-channel supply chain with one manufacturer, which sells products through a direct channel and a retailer. They constructed a single-period profit-sharing model between the manufacturers and retailers. The decision variables were the inventory levels of the direct and retailer's channel with a retailer service constraint. Nonetheless, they neither considered the dualchannel warehouse nor the operational costs. Yao et al. (2009) studied a dual-channel supply chain comprising one manufacturer and one retailer. They studied a centralized inventory strategy, the Stackelberg inventory strategy, and 3PL e-tail operation strategy. They proposed a single-period 
model to obtain the inventory level for the manufacturer and for the retailer that maximizes the expected profit. However, they did not deal with the dual-channel warehouse in terms of structure or at the operational level. Khouja (2003) proposed a 3-stage supplier-manufacturer-customer supply chain model. They employed a periodic review inventory policy and defined inventory coordination mechanisms such as cycle time and number of orders. Nonetheless, they did not consider the dual-channel warehouse, its structure, or operations.

Reviewing the inventory management research stream, we found that the $(\mathrm{Q}, \mathrm{R})$ policy is extensively used in the literature. Many of the recently published articles have considered the $(\mathrm{Q}$, R) policy (Sarkara et al., 2015). The advanced inventory management systems and the reduced cost of radio frequency identification technology have made the continuous review inventory control policy $(\mathrm{Q}, \mathrm{R})$ a very attractive approach. In the modeling process, the annual ordering cost, annual holding cost, annual backordering cost, or annual lost sales cost are considered subject to some service constraint, which is typically the fill rate. Generally, it is difficult to obtain a closedform solution, and a well-known iterative algorithm is used to obtain the optimal order quantities. This has led to the use of many heuristics or approximation approaches in solving the model.

As observed, all the reviewed studies above did not consider the dual-channel supply chain inventory strategies in the context of a dual-channel distribution system. They allocated online demand to the manufacturer warehouse without studying the implications that online fulfillment capability has for the dual-channel warehouse structure and operations. Additionally, they did not consider the dual-channel warehouse structure, operations, or capacities. Finally, they considered deterministic lead times. This study fills these research gaps by examining the inventory strategies for a dual-channel supply chain while considering the dual-channel warehouse structure, operations, space constraint, stochastic demand, and lead time. It combines the research fields of dual-channel warehouse operations, structure designs, and capacity management as well.

\section{Warehouse operations and management in dual-channel supply chains}

The literature on dual-channel warehouse operations demonstrates the importance of picking processes, particularly with regard to direct channel fulfillment processes. Hübner et al. (2015) reviewed the operation structures of multi-channel retailing, including network design, inventory management, warehouse operations, and capacity management. They discussed the structures and challenges in multi-channel warehouse operations. They concluded that the main driver in multi- 
channel operations was an efficient integration of warehouse operations. They provided interesting insights on multi-channel operations. However, their findings were based on a literature survey, and the analysis they presented was not based on an application of the model to a real case study or numerical analysis.

Allgor et al. (2003) studied e-retailing settings and the effects they had on conventional inventory models. The authors divided warehouses into two areas: a deep storage area and a low storage picking area. They proposed a multi-item, two-stage periodic review model (R, T). A heuristic-based algorithm was proposed as a solution approach. Xu (2005) presented a periodic review inventory model for a single-channel e-tailor order fulfillment process considering warehouse space. To optimize warehouse operations, the warehouse was divided into two areas. One of these areas had a low density for order picking and the other had a high density for stocking items and replenishing the center's picking area using a periodic review inventory control policy. They considered a stochastic demand; however, they assumed a deterministic lead time. This study differs from that of Allgor et al. (2003) and Xu (2005) in the following two aspects: first, this study considers the dual-channel supply chain with both online and offline demands while the references dealt with a single channel only, i.e., e-tailor supply chain; second, the proposed model in this study is based on a continuous review inventory policy $(\mathrm{Q}, \mathrm{R})$ and specifically considers warehouse structure, operations, and capacities, while the references proposed a periodic review model $(\mathrm{R}, \mathrm{T})$. The similarity between our studies and those in the references is the division of the warehouse into two stage areas.

Related to the dual-channel warehouse in terms of division of space, the forward-reserve problem has already been modeled in previous studies. Hackman and Rosenblatt (1990) developed a model to determine which items to assign to the automated storage and retrieval system (AS/RS), where the warehouse was divided into two areas: AS/RS area and the area for manual or semiautomated material handling system. Instead of deciding which area each item should be placed in, this study decides the inventory policy for each item, and both areas have all items to serve online and offline orders. Bartholdi and Hackman (2008) investigated how to allocate a forward pick area in a distribution center. The dual-channel warehouse in this study offers delivery operations in both areas. The previous works investigated the forward-reserve problem with a single-channel and deterministic demand, while no ordering and backordered costs were considered. 
It is noted that the e-commerce industry has been using the "multi-channel warehouse" for several years, but only a couple of articles discussing such warehouse can be found in the literature, such as that by Hübner et al. (2015). Furthermore, none of those articles provided quantitative analysis for the multi-channel warehouse. A comprehensive literature review indicates that some mathematical inventory management models have been proposed for dual-channel supply chains; however, there is a lack of research that investigates the warehouse structure, operations, and capacity in a dual-channel context. Some articles have addressed the warehouse operations and capacity management of single-channel warehouses, but they have not addressed these in a dualchannel context. Therefore, to the best of our knowledge, inventory management, warehouse structure, operations, and capacity management have not been harmonized for an integrated model in a dual-channel context.

\section{Mathematical model formulation}

\subsection{Problem statement}

The main objectives of a manufacturer's warehouse are to increase space utilization, reduce operation cost, and fulfill orders quickly and reliably. These objectives are usually conflicting. To obtain high space utilization, we need to store items in a high-density storage area such as pallets or high beam storage systems. Meanwhile, efficient order picking for online orders, which are usually of small sizes, requires the picker to have full access to the stored items, which means that they need to be displayed in low-density storage areas such as racks or stands. At the same time, to provide a high level of service, the warehouse needs to have an optimal inventory level for each item.

We consider the emerging dual-channel warehouse to fulfill both online and offline orders. To optimize the operation, the structure design of the dual-channel warehouse reflects the different features of the two different orders: the warehouse is divided into two storage areas with different inventory levels. One area, called Stage 1 area, is usually for picking items that are displayed on shelves or stands, packing, and shipping small size online customer orders, while the other area, called Stage 2 area, is for deep storage, to store inventory, replenish Stage 1, and fulfill offline retailer's large size orders. Orders from the supplier or the manufacturer will usually come in pallets and be stored first in Stage 2 area. Together, the areas form a two-echelon serial inventory control system, which is shown in Figure 2. 
Our goal is to develop a decision support tool for the operational and strategic decision related to the dual-channel warehouse with both online and offline fulfillment capability. On the operational level, we intend to assist in determining the optimal inventory level, item flow between the deep storage area and online picking area, as well as the replenishment frequency of both areas. On the strategic level, we will analyze the effect of the warehouse structure and space reserved for the online picking area on the total operating cost.

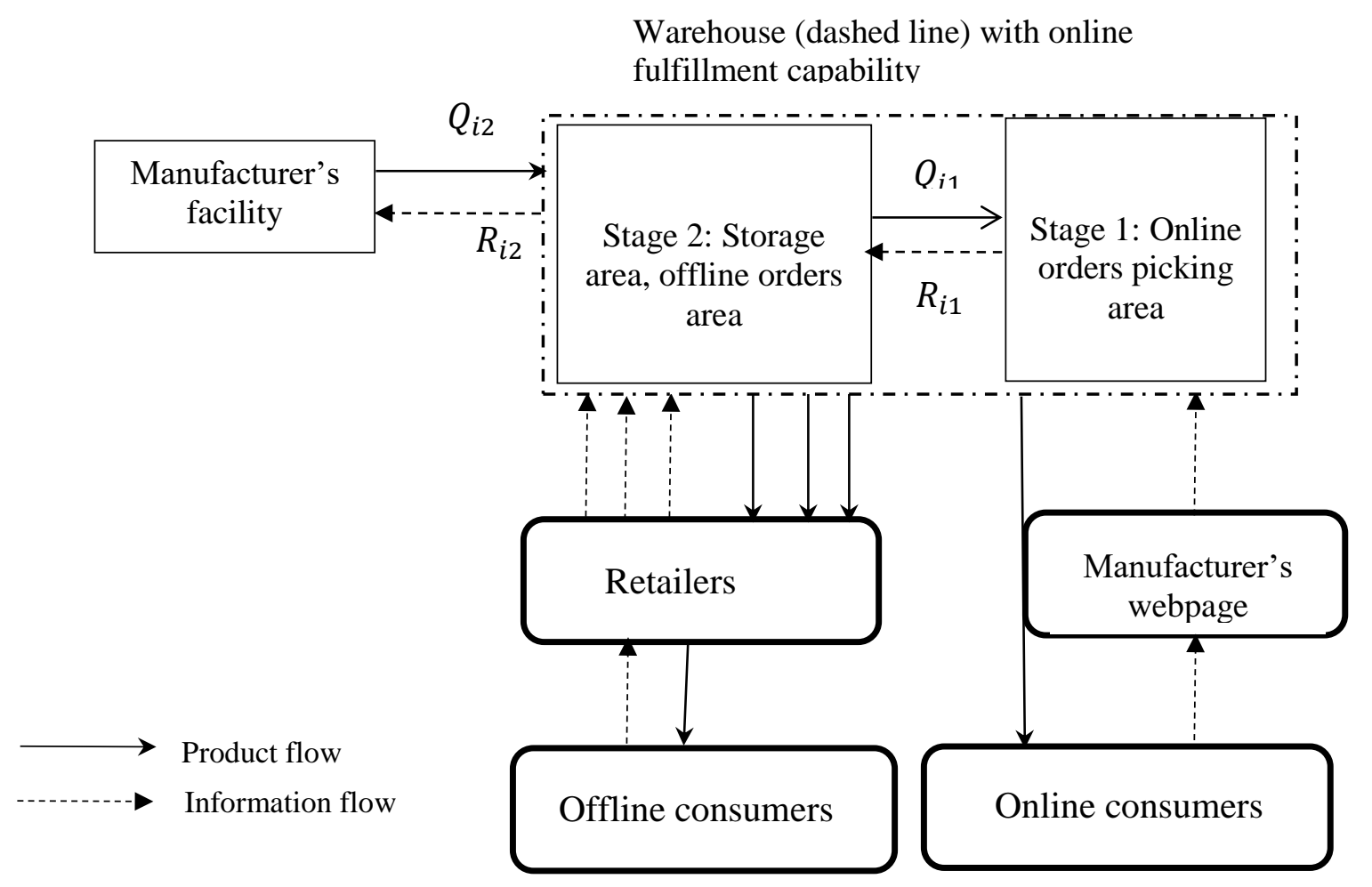

Figure 2. Dual-channel warehouse with online fulfillment capability

\subsection{Notations and assumptions}

\subsubsection{Notations}

The notations used in developing the mathematical model are given as follows:

$i$ : Item index

$j$ : Stage index, where $j=1$ for warehouse area dedicated to satisfying online demand (online picking area), and $j=2$ for warehouse area dedicated to satisfying both retail and dedicated online area demands 
$L_{i j}$ : Length of lead time for item $i$ in stage $j$ (random variable)

$D_{i j}$ : Expected annual demand for item $i$ in stage $j$

$h_{i j}$ : Holding cost per unit time for item $i$ at stage $j$

$b_{i j}$ : Backorder cost per unit for item $i$ at stage $j$

$A_{i j}$ : Ordering cost per order for item $i$ at stage $j$

$x_{i j}$ : Demand during lead time (DDLT, random variable) for item $i$ in stage $j$

$f\left(x_{i j}\right)$ : Probability density function of lead-time demand for item $i$ at stage $j$

$\gamma_{i j}$ : Storage space required by a stock keeping unit in stage $j$

$\alpha$ : Minimum required probability that total order quantities will be within warehouse space

$S$ : Available space of the entire warehouse

Decision variables

$Q_{i 2}$ : Order quantity for item $i$ in Stage 2

$Q_{i 1}$ : Order quantity for item $i$ in Stage 1

$R_{i 2}$ : Reorder point when new order is placed for item $i$ in Stage 2

$R_{i 1}$ : Reorder point when new order is placed for item $i$ in Stage 1

3.2.2 Assumptions and preliminary analysis

1) The demand rate per unit time (day or week) during lead time is a random variable with a mean of $\mu_{d_{i j}}$ and standard deviation of $\sigma_{d_{i j}}$. We assumed that the demand standard deviation is very small relative to the mean demand; therefore, the probability of negative demand is negligible (Lee, 2005; Zhang et al., 2006).

2) The lead time $L_{i j}$ is a random variable with a mean of $\mu_{L_{i j}}$ and a standard deviation of $\sigma_{L_{i j}}$.

3) If the DDLT for item $i$ in stage $j$ is in a situation where the demand and lead time are normally distributed and statistically independent, then the mean and standard deviation of the DDLT are

$$
\mu_{x_{i j}}=\mu_{L_{i j}} \times \mu_{d_{i j}} \text { and } \sigma_{x_{i j}}=\sqrt{\mu_{L_{i j}} \times \sigma_{d_{i j}}^{2}+\mu_{d_{i j}}^{2} \times \sigma_{L_{i j}}^{2}} \text {. }
$$

In the situation where there is a fixed lead time,

$\mu_{x_{i j}}=L_{i j} \times \mu_{d_{i j}}$ and $\sigma_{x_{i j}}=\sqrt{L_{i j} \times \sigma_{d_{i j}}^{2}}$.

In the situation where there is a uniform distribution of the demand and lead time, the demand joint distribution function is defined as 
$f\left(x_{i j}\right)=\frac{1}{\left(d_{M_{i j}}-d_{m_{i j}}\right)\left(t_{M_{i j}}-t_{m_{i j}}\right)}$.

Moreover, the mean of the DDLT is

$\mu_{x_{i j}}=\frac{\left(d_{M_{i j}}+d_{m_{i j}}\right)\left(t_{M_{i j}}+t_{m_{i j}}\right)}{4}$,

and the standard deviation of the DDLT is

$\sigma_{x_{i j}}=\sqrt{\frac{\left(d_{M_{i j}}-d_{m_{i j}}\right)^{2}\left(t_{M i j}-t_{m_{i j}}\right)^{2}+3\left(d_{M_{i j}}+d_{m_{i j}}\right)^{2}\left(t_{M_{i j}}-t_{m_{i j}}\right)^{2}+3\left(d_{M_{i j}}-d_{m_{i j}}\right)^{2}\left(t_{M_{i j}}+t_{m_{i j}}\right)^{2}}{144}}$

where $\left(t_{m_{i j}}, t_{M_{i j}}\right)$ are respectively the lower and upper limits of the uniform lead time demand distribution, and $\left(d_{m_{i j}}, d_{M_{i j}}\right)$ are the lower and upper limits of the uniform demand distribution respectively (Das and Hanaoka, 2014). In the retail environment, where the demand per period is normally large, the normal distribution is an appropriate modeling choice (Hadley and Whitin, 1963; Silver and Peterson, 1985), particularly if we have sufficient historical data from which the mean and the standard deviation can be drawn. However, a uniform distribution is commonly used for new items in situations where such historical data is not available (Wanke, 2008). Usually, the warehouse serves many retailers via the offline channel. The integrated offline demand is large and thus, it can be assumed to reasonably follow the normal distribution or the uniform distribution.

The uniform and normal distributions are both typically used to describe uncertain demands/lead time. Our model proposed in the next section is independent of the probability distribution unless it is continuous, and works for other probability distributions such as the exponential distribution. However, solving the problem, particularly those with closed-form solutions, depends on the different distributions.

4) After conducting a literature review on the dual-channel demand structure, we found that the demand is categorized within two streams. In the first stream, the demand of each channel is treated as an independent random variable. The total system demand is the aggregation of both channel demands (Alptekinoglu and Tang, 2005; Lee, 2005; Abdul-Jalbar et al., 2006; Seifert et al., 2006; Zhang et al., 2006; Bichescu and Fry, 2009). In the second stream, the demand is correlated, and the total system demand, which follows a specific distribution, is known. Then it is split between the individual channels (Lippman and McCardle, 2004; Tsay and Agrawal, 2004; Chiang and Monahan, 2005; Yao et al., 2005). 
In our proposed model, we considered both cases of independent and correlated demand. Additionally, regardless of the demand structure, we have assumed that customer channel loyalty $\beta_{j}$ ranges between $0-100 \%$. This means that with $100 \%$ channel loyalty, sales are lost in situations where there is a sales channel absence. We assumed that online and retailer demand is independent (the assumption is relaxed in Section 5). Consequently, as an illustrative example, the single-item (we dropped the $i$ index for simplicity) system demand is given as follows:

Stage 2 demand will be the aggregation of the online and offline demand, i.e., $D_{2}=D_{r}+D_{d}$ and the demand at Stage 1 is $D_{1}=D_{d}$. In the case where we have a single-retailer channel, Stage 2 demand will be the retailer demand plus the percentage of customers willing to switch from the online channel, i.e., $D_{2}=D_{r}+\beta_{1} D_{d}$. In cases where there is only an online channel, Stage 2 demand will be the aggregation of the online demand plus the percentage of customers willing to switch from the retailer channel: $D_{2}=D_{d}+\beta_{2} D_{r}$.

Stage 1 demand is given by the following:

$D_{1}=D_{d}$ where there is a dual sales channel, $D_{1}=0$ where there is only a retailer channel, $D_{1}=D_{d}+\beta_{2} D_{r}$ where there is only an online channel.

5) This study employs a continuous review inventory control policy, also known as the $(\mathrm{Q}, \mathrm{R})$ policy. Such a policy is also used extensively in the existing literature, such as in articles by Khouj and Stylianou (2009) and Sarkara et al. (2015).

6) A demand that cannot be immediately satisfied by the inventory is backordered with a penalty cost (Hadley and Whitin, 1963; Nahmias, 2013). This is more common when dealing with online demand as online orders have more flexible delivery times than offline orders.

7) Each stage (each area in the warehouse) has a reorder point that corresponds to an installation inventory for that stage. The reorder point is equal to the expected DDLT plus the safety stock, which is a function of stock-out probability during lead time. Stage 1 receives internal shipments from Stage 2, while Stage 2 receives shipments from the supplier.

8) The orders do not cross, because a single supplier is used or one outstanding order is assumed. 


\subsection{Mathematical models}

The problem is to determine the inventory policy for both stages in the dual-channel warehouse so that the total expected cost is minimized, subject to the warehouse capacity limit. The formulation of the problem is given as follows.

The objective of the problem is to minimize the annual total expected cost, denoted as $\mathrm{C}\left(Q_{i 2}, R_{i 2}, Q_{i 1}, R_{i 1}\right)$, which comprises ordering, holding, and shortage costs. For a given inventory policy $\left(Q_{i j}, R_{i j}\right)$, the average inventory level for Stage 1 is the average cycle inventory plus the safety inventory, approximately expressed as $Q_{i 1} / 2+R_{i 1}-\mu_{x_{i 1}}$, where $R_{i 1}-\mu_{x_{i 1}}$ is the safety stock. The approximation on the average inventory is reasonable for many real cases and is widely used in textbooks and in the literature (De Bodt and Graves, 1985; Yano, 1985; Zipkin, 1986; Ghalebsaz-Jeddi et al., 2004; Khouja and Stylianou, 2009; Nahmias, 2013; Fattahi et al., 2015). Similarly, the average inventory level for Stage 2 is approximately expressed as $Q_{i 2} / 2+R_{i 2}-\mu_{x_{i 2}}$. Thus, the annual total expected cost is formulated as follows with respect to the decision variables $Q_{i 2}, R_{i 2}, Q_{i 1}, R_{i 1}$.

\section{Objective: Min the total expect cost}

$$
\begin{aligned}
\mathrm{C}\left(\mathrm{Q}_{i 2}, \mathrm{R}_{i 2}, \mathrm{Q}_{i 1}, \mathrm{R}_{i 1}\right) \\
=\sum_{i} \frac{A_{i 2} \mathrm{D}_{i 2}}{\mathrm{Q}_{i 2}}+\sum_{i} \frac{A_{i 1} \mathrm{D}_{i 1}}{\mathrm{Q}_{i 1}}+\sum_{i} \mathrm{~h}_{i 2}\left[\left(\frac{\mathrm{Q}_{i 2}}{2}\right)+\left(\mathrm{R}_{i 2}-\mu_{x_{i 2}}\right)\right] \\
+\sum_{i} \mathrm{~h}_{i 1}\left[\left(\frac{\mathrm{Q}_{i 1}}{2}\right)+\left(\mathrm{R}_{i 1}-\mu_{x_{i 1}}\right)\right]+\sum_{i} \frac{\mathrm{b}_{i 2} \mathrm{D}_{i 2}}{\mathrm{Q}_{i 2}}\left[\int_{\mathrm{R}_{i 2}}^{\infty}\left(x_{i 2}-\mathrm{R}_{i 2}\right) f\left(x_{i 2}\right) \mathrm{d} x_{i 2}\right] \\
+\sum_{i} \frac{\mathrm{b}_{i 1} \mathrm{D}_{i 1}}{\mathrm{Q}_{i 1}}\left[\int_{\mathrm{R}_{i 1}}^{\infty}\left(x_{i 1}-\mathrm{R}_{i 1}\right) f\left(x_{i 1}\right) \mathrm{d} x_{i 1}\right] .
\end{aligned}
$$

The first and second terms of the objective function (6) refer to the annual ordering cost, which is the order cost multiplied by the number of cycles. The third and fourth terms refer to the annual approximated holding cost. The fifth and sixth terms represent the annual backorder cost, which is equal to the backorder cost multiplied by the expected number of shortages per cycle.

We consider the warehouse capacity constraint. Because of uncertain demand, we set the probability that the total simultaneous items inventory within the warehouse space when the order is received will not be smaller than $\alpha$. Then we have the following constraints:

$P\left[\left(\sum_{i} \gamma_{i 2}\left(Q_{i 2}+R_{i 2}-x_{i 2}\right)+\gamma_{i 1}\left(Q_{i 1}+R_{i 1}-x_{i 1}\right)\right) \leq S\right] \geq \alpha$, 
$R_{i j}, Q_{i j} \geq 0 \forall i, j$

The space constraint (2) can be written as

$P\left[\sum_{i} \gamma_{i 2} x_{i 2}+\gamma_{i 1} x_{i 1} \geq \sum_{i}\left(\gamma_{i 2}\left(Q_{i 2}+R_{i 2}\right)+\gamma_{i 1}\left(Q_{i 1}+R_{i 1}\right)\right)-S\right] \geq \alpha$,

which can be reformulated as

$\sum_{i}\left(\gamma_{i 2}\left(Q_{i 2}+R_{i 2}\right)+\gamma_{i 1}\left(Q_{i 1}+R_{i 1}\right)\right) \leq S+\mu_{Y}+z_{1-\alpha} \sigma_{Y}$,

where

$Y=\sum_{i} \sum_{j} \gamma_{i j} x_{i j}, \mu_{Y}=\sum_{i} \sum_{j} \gamma_{i j} \mu_{i j}$, and $\sigma_{Y}^{2}=\sum_{i} \sum_{j} \gamma_{i j}{ }^{2} \sigma_{i j}$,

and $z_{1-\alpha}$ is the value of the cumulative probability distribution of the demand at point $1-\alpha$ (Ghalebsaz-Jeddi et al., 2004).

A variant of the above constraint can be applied to either Stage 1 or Stage 2 in case we have a separate warehouse space limit. If the warehouse space constraint is applied to either area, we obtain the following:

For Stage 1, the constraint will be

$\sum_{i} \gamma_{i 1}\left(Q_{i 1}+R_{i 1}\right) \leq S_{1}+\mu_{Y 1}+z_{1-\alpha} \sigma_{Y 1}$,

where $\mu_{Y 1}=\sum_{i} \gamma_{i 1} \mu_{i 1}, \sigma_{Y 1}^{2}=\sum_{i} \gamma_{i 1}^{2} \sigma_{i 1}$, and $S_{1}$ is the area dedicated for Stage 1 .

Meanwhile, if the space constraint is applied to Stage 2, we obtain

$\sum_{i} \gamma_{i 2}\left(Q_{i 2}+R_{i 2}\right) \leq S_{2}+\mu_{Y 2}+z_{1-\alpha} \sigma_{Y 2}$

where $\mu_{Y 2}=\sum_{i} \gamma_{i 2} \mu_{i 2}, \sigma_{Y 2}^{2}=\sum_{i} \gamma_{i 2}^{2} \sigma_{i 2}$, and $S_{2}$ is the area dedicated for Stage 2 .

The model formulated using (6), (8), and (10), denoted as problem $(P)$, is a constrained nonlinear program, where it is difficult to find a closed-form solution. A detailed solution approach is discussed in the next section.

\section{Solution}

Before introducing the solution approach, we define the expected shortage per cycle (ESC) and cycle service level (CSL). Silver and Peterson (1985) defined the ESC for the single-stage case. We extended the ESC to the dual-stage case as follows: 
$\operatorname{ESC}\left(R_{i j}\right)=\int_{R_{i j}}^{\infty}\left(x_{i j}-R_{i j}\right) f\left(x_{i j}\right) d x_{i j}$,

$C S L: \int_{0}^{R_{i j}} f\left(x_{i j}\right) d x_{i j}$.

The constrained nonlinear problem given is a convex problem, which is described by the following theorem.

Theorem 1: The nonlinear programming problem $(P)$ is convex.

Proof. Please see Appendix A.

Because problem $P$ is a convex nonlinear program, this implies that the solution of the problem $(P)$ is unique and satisfies the necessary Karush-Kuhn-Tucker (KKT) conditions. We consider a Lagrange function

$$
\begin{aligned}
L\left(Q_{i 2}, R_{i 2}, Q_{i 1},\right. & \left.R_{i 1}, \theta\right) \\
& =\sum_{i} \frac{A_{i 2} D_{i 2}}{Q_{i 2}}+\sum_{i} \frac{A_{i 1} D_{i 1}}{Q_{i 1}}+\sum_{i} h_{i 2}\left[\left(\frac{Q_{i 2}}{2}\right)+\left(R_{i 2}-\mu_{x_{i 2}}\right)\right] \\
& +\sum_{i} h_{i 1}\left[\left(\frac{Q_{i 1}}{2}\right)+\left(R_{i 1}-\mu_{x_{i 1}}\right)\right]+\sum_{i} \frac{b_{i 2} D_{i 2}}{Q_{i 2}}\left[\int_{R_{i 2}}^{\infty}\left(x_{i 2}-R_{i 2}\right) f\left(x_{i 2}\right) d x_{i 2}\right] \\
& +\sum_{i} \frac{b_{i 1} D_{i 1}}{Q_{i 1}}\left[\int_{R_{i 1}}^{\infty}\left(x_{i 1}-R_{i 1}\right) f\left(x_{i 1}\right) d x_{i 1}\right] \\
& +\theta\left[\sum_{i}\left(\gamma_{i 2}\left(Q_{i 2}+R_{i 2}\right)+\gamma_{i 1}\left(Q_{i 1}+R_{i 1}\right)\right)-S-\mu_{Y}-z_{1-\alpha}\right]
\end{aligned}
$$

where $\theta$ is the Lagrange multiplier for the space constraint. Then we can find the optimal solution via the following KKT first-order conditions:

From $\frac{\partial L}{\partial Q_{i j}}=0$,

we obtain $-\frac{A_{i j} D_{i j}}{Q_{i j}{ }^{2}}+\frac{h_{i j}}{2}-\frac{b_{i 1} D_{i 1}}{Q_{i j}{ }^{2}}\left[\int_{R_{i 1}}^{\infty}\left(x_{i 1}-R_{i 1}\right) f\left(x_{i 1}\right) d x_{i 1}\right]+\gamma_{i j} \theta=0$.

Rearrange to obtain

$Q_{i j}=\sqrt{\frac{2 D_{i j}\left(A_{i j}+b_{i j} E S C\left(R_{i j}\right)\right)}{h_{i j}+2 \gamma_{i j} \theta}}$.

From $\frac{\partial L}{\partial R_{i j}}=0$, 
we obtain

$$
h_{i j}+\frac{b_{i j} D_{i j}}{Q_{i j}}\left[f\left(x_{i j}\right) d x_{i j}\right]+\gamma_{i j} \theta=0 .
$$

Rearrange to obtain

$$
\int_{R_{i j}}^{\infty} f\left(x_{i j}\right) d x_{i j}=\frac{\left(h_{i j}+\gamma_{i j} \theta\right) Q_{i j}}{b_{i j} D_{i j}} .
$$

We also have

$\frac{\partial L}{\partial \theta}=\sum_{i} \sum_{j} \gamma_{i j}\left(Q_{i j}+R_{i j}\right)-S-\mu_{Y}-z_{1-\alpha} \sigma_{y} \leq 0$ and

$R_{i j}, Q_{i j}, \theta \geq 0 \forall i, j$

If (18) is substituted into (20), we obtain

$$
\int_{R_{i j}}^{\infty} f\left(x_{i j}\right) d x_{i j}=\frac{\left(h_{i j}+\gamma_{i j} \theta\right) \sqrt{\frac{2 D_{i j}\left(A_{i j}+b_{i j} E S C\left(R_{i j}\right)\right.}{h_{i j}+2 \gamma_{i j} \theta}}}{b_{i j} D_{i j}} .
$$

Squaring both sides and arranging, we obtain

$$
\left[\int_{R_{i j}}^{\infty} f\left(x_{i j}\right) d x_{i j}{ }^{2}\right] b_{i j}^{2} D_{i j}^{2}=\left(h_{i j}+\gamma_{i j} \theta\right)^{2}\left[\frac{2 D_{i j}\left(A_{i j}+b_{i j} E S C\left(R_{i j}\right)\right)}{h_{i j}+2 \gamma_{i j} \theta}\right] .
$$

Rearranging the above equation, we obtain

$b_{i j} D_{i j}\left(1-\operatorname{CSL}\left(R_{i j}\right)\right)^{2}-2\left(h_{i j}+\left(h_{i j}+1\right) \gamma_{i j} \theta\right) \operatorname{ESC}\left(R_{i j}\right)-\frac{2\left(h_{i j}+\left(h_{i j}+1\right) \gamma_{i j} \theta\right) A_{i j}}{b_{i j}}=0$.

We will discuss the solution approaches for both uniform and normal demand distributions. For each distribution, we also investigate two situations: with and without warehouse space constraints (or inactive constraint). We discuss the problem without constraint because we can develop closed-form solutions for the situation, which may occur in practice.

\subsection{Uniform distribution of demand and lead time}

This section provides the solution when the demand and lead time follow a uniform distribution. The use of uniform demand is a common approach in the case of new products whenever one does not have sufficient historical data to obtain the parameters of the probability density function of the demand or lead time (e.g., the normal distribution mean and standard 
deviation) (Wanke, 2008; Das and Hanaoka, 2014).

\subsubsection{Uniform distribution and deterministic lead time without space constraint}

Assume that the demand follows the uniform distribution $\left(0, U_{i j}\right)$; then

$\int_{R_{i j}}^{\infty} f\left(x_{i j}\right) d x_{i j}=\left(1-\frac{R_{i j}}{U_{i j}}\right)$,

and

$\int_{R_{i j}}^{\infty}\left(x_{i j}-R_{i j}\right) f\left(x_{i j}\right) d x_{i j}=\frac{U_{i j}}{2}-R_{i j}+\frac{R_{i j}^{2}}{2 U_{i j}}$.

If (26) and (27) are substituted into (25), then

$b_{i j} D_{i j}\left(1-\frac{2 R_{i j}}{U_{i j}}+\frac{R_{i j}^{2}}{U_{i j}^{2}}\right)-2 h_{i j}\left(\frac{U_{i j}}{2}-R_{i j}+\frac{R_{i j}^{2}}{2 U_{i j}}\right)-\left(\frac{2 h_{i j} A_{i j}}{b_{i j}}\right)=0$.

Rearranging the above equation, we obtain

$\left(\frac{b_{i j}}{U_{i j}^{2}}-\frac{h_{i j}}{U_{i j}}\right) R_{i j}^{2}-\left(2 h_{i j}-\frac{2 b_{i j} D_{i j}}{U_{i j}}\right) R_{i j}+\left(b_{i j} D_{i j}-h_{i j} U_{i j}-\frac{2 h_{i j} A_{i j}}{b_{i j}}\right)=0$.

The result is a quadratic equation with one unknown, $R_{i j}$. Then we can determine the optimal reorder point for each stage:

$$
R_{i j}=\frac{-\left(2 h_{i j}-\frac{2 b_{i j} D_{i j}}{U_{i j}}\right) \pm \sqrt{\left(2 h_{i j}-\frac{2 b_{i j} D_{i j}}{U_{i j}}\right)^{2}-4\left(\frac{b_{i j}}{U_{i j}^{2}}-\frac{h_{i j}}{U_{i j}}\right)\left(b_{i j} D_{i j}-h_{i j} U_{i j}-\frac{2 h_{i j} A_{i j}}{b_{i j}}\right)}}{2\left(\frac{b_{i j}}{U_{i j}^{2}}-\frac{h_{i j}}{U_{i j}}\right)} .
$$

With $R_{i j}$ calculated above, we can determine the optimal order quantity $Q_{i j}$ using (18).

\subsubsection{Uniform distribution and stochastic lead time without space constraint}

In the case of a stochastic demand and stochastic lead time, an integration should be obtained using the joint distribution function of two random variables. If the demand by unit time follows the uniform distribution $\mathrm{U} \sim\left(0, d_{M}\right)$ and the lead time $\mathrm{U} \sim\left(0, t_{M}\right)$, then

$\int_{R_{i j}}^{\infty} f\left(x_{i j}\right) d x_{i j}==1-\left[\frac{R_{i j}}{\left(d_{M_{i j}} t_{M_{i j}}\right)}\left(1+\ln \left(\frac{d_{M_{i j}} t_{M_{i j}}}{R_{i j}}\right)\right)\right]$,

and 


$$
\begin{aligned}
& \int_{R_{i j}}^{\infty}\left(x_{i j}-R_{i j}\right) f\left(x_{i j}\right) d x=\frac{1}{\left(2 d_{M_{i j}} t_{M_{i j}}\right)}\left[\frac{t_{M_{i j}}^{2}}{2}\left(d_{M_{i j}}^{2}-\frac{R_{i j}^{2}}{t_{M_{i j}}^{2}}\right)-R_{i j}^{2} \ln \left(\frac{d_{M_{i j}} t_{M_{i j}}}{R_{i j}}\right)\right]- \\
& R_{i j}\left[1-\left(\frac{R_{i j}}{\left(d_{M_{i j}} t_{M_{i j}}\right)}\left(1+\ln \left(\frac{d_{M_{i j}} t_{M_{i j}}}{R_{i j}}\right)\right)\right] .\right.
\end{aligned}
$$

When (31) and (32) are substituted into (25), then

$$
\begin{aligned}
b_{i j} D_{i j}\left[\left(1-\left(\frac{R_{i j}}{\left(d_{M_{i j}} t_{M_{i j}}\right)}\left(1+\ln \left(\frac{d_{M_{i j}} t_{M_{i j}}}{R_{i j}}\right)\right)\right)\right)\right]^{2} \\
-2 h_{i j}\left[\left(\frac{1}{\left(2 d_{\left.M_{i j} t_{M_{i j}}\right)}\right)}\right)\left(\frac{t_{M_{i j}}^{2}}{2}\left(d_{M_{i j}}^{2}-\frac{R_{i j}^{2}}{t_{M_{i j}}^{2}}\right)-R_{i j}{ }^{2} \ln \left(\frac{d_{M_{i j}} t_{M_{i j}}}{R_{i j}}\right)\right)\right. \\
-R_{i j}\left(1-\left(\frac{R_{i j}}{\left(d_{M_{i j}} t_{M_{i j}}\right)}\left(1+\ln \left(\frac{d_{M_{i j}} t_{M_{i j}}}{R_{i j}}\right)\right)\right)\right]-\frac{2 h_{i j} A_{i j}}{b_{i j}}=0 .
\end{aligned}
$$

Equation (33) is nonlinear with the single variable of reorder point $R_{i j}$, which can be solved using an Excel spreadsheet, or using an advanced math program, such as Matlab. With the calculated optimal reorder point, we can determine the optimal order quantity $Q_{i j}$ using (18) for this case.

\subsubsection{Uniform distribution with space constraint}

When there is a warehouse space constraint, we can determine the optimal solution by solving the dual problem of the Lagrangian function given in (16):

$\operatorname{Max}_{\theta} \operatorname{Min} L\left(Q_{i 2}, R_{i 2}, Q_{i 1}, R_{i 1}, \theta\right)$.

Actually, we can solve the problem first without considering the warehouse constraint through equations (30) or (33), and then check the constraint (10). If the constraint is satisfied,

then we determine the optimal solution for the original problem. Otherwise, we can use either a subgradient method or bisection search to solve the Lagrangian dual problem. Because the problem is convex, there is a unique solution. In this case, based on (21), we have

$\sum_{i} \sum_{j} \gamma_{i j}\left(Q_{i j}+R_{i j}\right)-S-\mu_{Y}-z_{1-\alpha} \sigma_{y}=0$. 
For a given value of $\theta, \mathrm{Q}_{i j}$ and $\mathrm{R}_{i j}$ can be calculated using (30) or (33); then they can be substituted into equation (34). This reduces the problem to a solution for one equation with one unknown $\theta$ :

$g(\theta)=\sum_{i} \sum_{j} \gamma_{i j}\left(Q^{\sim}{ }_{i j}+R^{\sim}{ }_{i j}\right)-S-\mu_{Y}-z_{1-\alpha}=0$.

As there is one variable and solution uniqueness, we can use the bisection search method to determine the solution. Therefore, if there are two distinct values of $\theta_{1}$ and $\theta_{2}$, such that $g\left(\theta_{1}\right)$ and $g\left(\theta_{2}\right)<0$, satisfying this condition is sufficient to allow using any onedimensional search technique to solve (30). The following algorithm is thus proposed.

1. Let $\theta_{1}=0$ and let $\theta_{2}$ be the smallest number, such that $g\left(\theta_{2}\right)<0$.

2. Let $Q_{1}^{\sim}, R_{1}^{\sim}$ be the solution when $\theta=\theta_{1}$, and let $Q_{2}^{\sim}, R_{2}^{\sim}$ be the solution when $\theta=\theta_{2}$.

3. Let $\theta=\frac{\theta_{1}+\theta_{1}}{2}$ and solve for $Q^{\sim}$ and $R^{\sim}$; find $g(\theta)$.

4. If $g(\theta)>0$, then $\theta_{1}=\theta, Q_{1}^{\sim}=Q^{\sim}$, and $R_{1}^{\sim}=R^{\sim}$; if $g(\theta)<0$, then $\theta_{2}=\theta, Q_{2}^{\sim}=$ $Q^{\sim}$, and $R_{2}^{\sim}=R^{\sim}$.

5. If $\left(g\left(\theta_{1}\right)-g\left(\theta_{2}\right)\right)<\varepsilon_{g}$, then stop. Otherwise, go to 3 .

\subsection{Normal distribution demand and lead time}

In situations where sufficient historical data are available, the normal probability distribution for the demand and lead time can be generally estimated. Using the formulas presented in assumption 3, we can calculate the mean and standard deviation of the DDLT for deterministic or stochastic lead time. In the next sections, we will discuss the solution methodology when space constraint is active or inactive.

\subsubsection{Normal distribution without space constraint}

Given that $R_{i j}=\mu_{x_{i j}}+k \sigma_{x_{i j}}$, the expected shortage per cycle can be formulated as a function of the safety factor $k$, as presented by Kundu and Chakrabarti (2012). In situations where there is a single channel, the proposed formula may be extended to consider two-echelon dual-channel situations. If

$\operatorname{ESC}\left(R_{i j}\right)=\frac{\sigma_{x_{i j}}}{2}\left(\sqrt{1+k_{i j}^{2}}-k_{i j}\right)$, 
then the Lagrange function for the independent demand is

$$
\begin{aligned}
L\left(Q_{i j}, k_{i j}, \theta\right)= & \sum_{i} \sum_{j} \frac{A_{i j} D_{i j}}{Q_{i j}}+h_{i j}\left(\left(\frac{Q_{i j}}{2}\right)+k_{i j} \sigma_{x_{i j}}\right)+\frac{b_{i j} D_{i j}}{Q_{i j}}\left(\frac{\sigma_{x_{i j}}}{2}\left(\sqrt{1+k_{i j}^{2}}-k_{i j}\right)\right) \\
& +\theta\left[\sum_{i} \sum_{j} \gamma_{i j}\left(Q_{i j}+\mu_{x_{i j}}+k_{i j} \sigma_{x_{i j}}\right)-S-\mu_{Y}-z_{1-\alpha}\right] .
\end{aligned}
$$

Using the necessary KKT conditions for minimization problems, we obtain

$$
\frac{\partial L}{\partial Q_{i j}}=0,-\frac{A_{i j} D_{i j}}{Q_{i j}{ }^{2}}+\frac{h_{i j}}{2}-\frac{b_{i j} T_{i j}\left(\frac{\sigma_{x_{i j}}}{2}\left(\sqrt{1+k_{i j}^{2}}-k_{i j}\right)\right)}{Q_{i j}{ }^{2}}+\theta \gamma_{i j}=0 .
$$

This leads to

$$
\begin{aligned}
& Q_{i j}=\sqrt{\frac{2 D_{i j}\left[A_{i j}+b_{i j}\left(\frac{\sigma_{x_{i j}}}{2}\left(\sqrt{1+k_{i j}^{2}}-k_{i j}\right)\right)\right]}{h_{i j}+2 \gamma_{i j} \theta}}, \\
& \frac{\partial L}{\partial k_{i j}}=0, h_{i j} \sigma_{x_{i j}}+\frac{b_{i j} D_{i j}}{2 Q_{i j}}\left[\sigma_{x_{i j}}\left(\frac{k_{i j}}{\sqrt{1+k_{i j}^{2}}}-1\right)\right]+\theta \gamma_{i j} \sigma(x)_{i j}=0 .
\end{aligned}
$$

If we substitute (39) into (40), we have

$$
\frac{b_{i j} D_{i j}}{2 \sqrt{\frac{2 D_{i j}\left[A_{i j}+b_{i j}\left(\frac{\sigma_{x_{i j}}}{2}\left(\sqrt{1+k_{i j}^{2}}-k_{i j}\right)\right]\right.}{h_{i j}+2 \gamma_{i j} \theta}}}\left(\sigma_{x i j}\left(\frac{k_{i j}}{\sqrt{1+k_{i j}^{2}}}-1\right)\right)+h_{i j} \sigma_{x_{i j}}+\gamma_{i j} \sigma_{x_{i j}} \theta=0 .
$$

As the warehouse space constraint is not active, $\theta=0$; the remainder is one equation with one unknown. We may solve for $k_{i j}$ and consequently find $Q_{i j}$ and $R_{i j}$.

\subsubsection{Normal distribution with space constraint}

When the warehouse space constraint is active, we can apply the solution approach presented in Section 4.1.3. Similar to the KKT conditions on Lagrangian multiplier with a uniform distribution, we have 


$$
\frac{\partial L}{\partial \theta}=\sum_{i}\left(\gamma_{i 2}\left(Q_{i 2}+\sigma_{x_{i 2}} k_{i 2}\right)+\gamma_{i 1}\left(Q_{i 1}+\sigma_{x_{i 1}} k_{i 1}\right)\right)-S-\mu_{Y}-z_{1-\alpha} \leq 0
$$

With the bisection search method in Section 4.1.3, we can obtain the solution.

\section{Extension to correlated demands}

In this section, we extend the model to the situation where the demands from the two stages are correlated. We assume that the total demand $D$ is known and follows a specific distribution. To determine the Stage 2 and Stage 1 demand, we define a channel demand split factor $\varphi$, where the online demand $=\varphi D$ and retailer demand $=(1-\varphi) D$ (Yao et al., 2009). In this case, Stage 2 demand will be as follows:

$D_{2}=D$ where there is a dual sales channel;

$D_{2}=(1-\varphi D)+\beta_{1}(\varphi D)$ where there is only a retailer channel;

$D_{2}=\varphi D+\beta_{2}(1-\varphi) D$ where there is only an online channel.

Stage 1 demand will be

$D_{1}=\varphi D$ where there is a dual sales channel;

$D_{1}=0$ where there is only a retailer channel;

$D_{1}=\varphi D+\beta_{2}(1-\varphi) D$ where there is only an online channel.

The model given by (1) and (2) is changed with the following new objective function:

$$
\begin{aligned}
C\left(Q_{i 2}, R_{i 2}, Q_{i 1},\right. & \left.R_{i 1}\right) \\
& =\sum_{i} \frac{A_{i 2} D_{i}}{Q_{i 2}}+\sum_{i} \frac{A_{i 1} \varphi_{i} D_{i}}{Q_{i 1}}+\sum_{i} h_{i 2}\left[\left(\frac{Q_{i 2}}{2}\right)+\left(R_{i 2}-\mu_{x_{i 2}}\right)\right] \\
& +\sum_{i} h_{i 1}\left[\left(\frac{Q_{i 1}}{2}\right)+\left(R_{i 1}-\mu_{x_{i 1}}\right)\right]+\sum_{i} \frac{b_{i 2} D_{i 2}}{Q_{i 2}}\left[\int_{R_{i 2}}^{\infty}\left(x_{i 2}-R_{i 2}\right) f\left(x_{i 2}\right) d x_{i 2}\right] \\
& +\sum_{i} \frac{b_{i 1} D_{i 1}}{Q_{i 1}}\left[\int_{R_{i 1}}^{\infty}\left(x_{i 1}-R_{i 1}\right) f\left(x_{i 1}\right) d x_{i 1}\right] .
\end{aligned}
$$

S.T.

$\sum_{i}\left(\gamma_{i 2}\left(Q_{i 2}+R_{i 2}\right)+\gamma_{i 1}\left(Q_{i 1}+R_{i 1}\right)\right) \leq S+\mu_{Y}+z_{1-\alpha} \sigma_{Y}$

Applying the solution approach presented in Section 4, we obtain 


$$
\begin{aligned}
L\left(Q_{i 2}, R_{i 2}, Q_{i 1}\right. & \left.R_{i 1}, \theta\right) \\
& =\sum_{i} \frac{A_{i 2} D_{i}}{Q_{i 2}}+\sum_{i} \frac{A_{i 1} \varphi_{i} D_{i}}{Q_{i 1}}+\sum_{i} h_{i 2}\left[\left(\frac{Q_{i 2}}{2}\right)+\left(R_{i 2}-\mu_{x_{i 2}}\right)\right] \\
& +\sum_{i} h_{i 1}\left[\left(\frac{Q_{i 1}}{2}\right)+\left(R_{i 1}-\mu_{x_{i 1}}\right)\right]+\sum_{i} \frac{b_{i 2} D_{i 2}}{Q_{i 2}}\left[\int_{R_{i 2}}^{\infty}\left(x_{i 2}-R_{i 2}\right) f\left(x_{i 2}\right) d x_{i 2}\right] \\
& +\sum_{i} \frac{b_{i 1} D_{i 1}}{Q_{i 1}}\left[\int_{R_{i 1}}^{\infty}\left(x_{i 1}-R_{i 1}\right) f\left(x_{i 1}\right) d x_{i 1}\right] \\
& +\theta\left[\sum_{i}\left(\gamma_{i 2}\left(Q_{i 2}+R_{i 2}\right)+\gamma_{i 1}\left(Q_{i 1}+R_{i 1}\right)\right)-S-\mu_{Y}-z_{1-\alpha}\right] .
\end{aligned}
$$

Using the necessary KKT conditions for minimization problems, we obtain

$$
b_{i 2} D_{i}\left(1-\operatorname{CSL}\left(R_{i 2}\right)\right)^{2}-2\left(h_{i 2}+\left(h_{i 2}+1\right) \gamma_{i 2} \theta\right) \operatorname{ESC}\left(R_{i 2}\right)-\frac{2\left(h_{i 2}+\left(h_{i 2}+1\right) \gamma_{i 2} \theta\right) A_{i 2}}{b_{i 2}}=0 \text {, }
$$

and

$b_{i 1} \varphi_{i} D_{i}\left(1-\operatorname{CSL}\left(R_{i 1}\right)\right)^{2}-2\left(h_{i 1}+\left(h_{i 1}+1\right) \gamma_{i 1} \theta\right) \operatorname{ESC}\left(R_{i 1}\right)-\frac{2\left(h_{i 1}+\left(h_{i 1}+1\right) \gamma_{i 1} \theta\right) A_{i 1}}{b_{i 1}}=0$,

$\frac{\partial L}{\partial \theta}=\sum_{i}\left(\gamma_{i 2}\left(Q_{i 2}+R_{i 2}\right)+\gamma_{i 1}\left(Q_{i 1}+R_{i 1}\right)\right)-S-\mu_{Y}-z_{1-\alpha} \sigma_{y} \leq 0$.

The solution methodology discussed for the independent demand model can be used to solve the correlated demand model for uniform and normal demands.

\section{Numerical examples and results}

In this section, we present numerical examples to verify the model and solution methods and to show the results for different demand distributions and the effects of demand features, warehouse space, and channel preference.

\subsection{Model parameters}

The parameters used for the experiment are based on the following observations: $\gamma_{1}>\gamma_{2}: \gamma$ represents the storage requirements in the warehouse per item. The assumption is based on the fact that the space required for each unit stored on pallets in Stage 2 is less than that in Stage 1 , where items are usually stored in low-density storage systems such as stands or racks to facilitate the individual item picking process. 
$D_{2}>D_{1}: D$ represents the demand. Offline demand is usually higher than online demand and the order size for an offline channel demand is larger than that for an online channel.

$A_{2}>A_{1}: A$ represents the ordering cost. The ordering process for Stage 1 aims to replenish items

for Stage 2, while the replenishment for Stage 2 requires ordering items from the supplier. Thus, the ordering cost for Stage 2 from the external supplier is higher.

$b_{2}>b_{1}: b$ represents the backorder cost. The backorder cost for the online channel is set to be less than that of the offline channel. The size of an online order is usually smaller than that of an offline order, and online orders have more flexible delivery times than offline orders (Agatz et al., 2008). Having a shortage in offline orders usually results in a higher penalty based on the contract signed between the manufacturers and retailers, while shortage in an online order has a lesser economic effect on the manufacturers; therefore, it is reasonable to have a shortage cost for Stage 2 that is higher than that for Stage 1.

$h_{1}>h_{2}: h$ represents the holding cost per item. The holding cost for the online channel is higher than that for the offline channel as the required space to store a unit in the online low-density area is greater than that in the offline high-density area.

\subsection{Numerical examples for independent demands}

We testes seven examples with different demand distributions and lead times for the case where the demands are independent. The input parameters used are given in Appendix B.

\section{Uniform distribution demand}

The first example is the dual-channel warehouse with independent demands that follow the uniform distribution, while the lead time is deterministic. Table 1 presents the obtained solution for two items with a uniform distribution demand. For instance, the order size for item 1 is 19,010 units, while the reorder point is 1003 units. Stage 2 replenishes Stage 1 with a batch of 335 units at a reorder point of 131 units. The total system cost is $\$ 33,566$.

Table 1. Inventory policy (Q, R) and cost for Example 1

\begin{tabular}{lllll}
\hline Order Quantity & & Reorder point & Total Cost \\
\hline $\mathrm{Q}_{11}$ & 335 & $\mathrm{R}_{11}$ & 131 & $\$ 33,566$ \\
$\mathrm{Q}_{12}$ & 19010 & $\mathrm{R}_{12}$ & 1003 & \\
$\mathrm{Q}_{21}$ & 142 & $\mathrm{R}_{21}$ & 51 & \\
$\mathrm{Q}_{22}$ & 7663 & $\mathrm{R}_{22}$ & 401 & \\
\hline
\end{tabular}


Example 2 is the same as Example 1 but without the warehouse constraint. In addition, both deterministic and stochastic lead times are considered. Table 2 presents the main parameters and results. The reorder point with a stochastic lead time (more safety stock) has increased to cope with higher uncertainty.

Table 2. Results for Example 2 with uniform demand and stochastic lead time

\begin{tabular}{|c|c|c|c|c|c|c|c|c|c|}
\hline & \multicolumn{6}{|c|}{ Input parameters } & \multicolumn{3}{|c|}{ Results $(\mathrm{Q}, \mathrm{R})$} \\
\hline & $d_{M}$ & $t_{M}$ & $\mathrm{D}$ & A & B & $\mathrm{h}$ & $\mathrm{R}$ & $\mathrm{Q}$ & Total Cost \\
\hline Deterministic & 60 & 0 & 60000 & 500 & 60 & 10 & 30 & 2388 & $\$ 29,809$ \\
\hline lead time & 50 & 0 & 45000 & 500 & 60 & 10 & 25 & 1985 & \\
\hline Stochastic lead & 60 & 15 & 60000 & 500 & 60 & 10 & 2135 & 18457 & $\$ 35,964$ \\
\hline time & 50 & 18 & 45000 & 500 & 60 & 10 & 2111 & 15753 & \\
\hline
\end{tabular}

\section{Normal distribution demand}

Table 3 presents the solution for Example 3, which has a normal distribution demand and deterministic lead time, but no space constraint. Example 4 is the same as Example 3 except that it has a stochastic lead time for Stage 2 (note that the lead time for Stage 1 remains deterministic). As we can observe, the reorder point for the stochastic case is higher than that of the deterministic case, and the total cost is increased from $\$ 5,561$ to $\$ 6,030$ as the inventory holding cost increases because we have to keep more safety stock to cope with higher demand variation.

Table 3. Results for Example 3 with normal distribution demand and deterministic lead time

\begin{tabular}{lllrlll}
\hline Order Quantity & & Reorder Point & \multicolumn{3}{l}{ Safety Factor } & Total Cost \\
\hline $\mathrm{Q}_{11}$ & 155 & $\mathrm{R}_{11}$ & 4 & $\mathrm{k}_{11}$ & 1.517 & $\$ 5,561$ \\
$\mathrm{Q}_{12}$ & 246 & $\mathrm{R}_{12}$ & 128 & $\mathrm{k}_{12}$ & 2.117 & \\
$\mathrm{Q}_{21}$ & 238 & $\mathrm{R}_{21}$ & 3 & $\mathrm{k}_{21}$ & 1.494 & \\
$\mathrm{Q}_{22}$ & 336 & $\mathrm{R}_{22}$ & 106 & $\mathrm{k}_{22}$ & 1.979 & \\
\hline
\end{tabular}

Table 4. Results for Example 4 with normal distribution demand and stochastic lead time

\begin{tabular}{lllrlll}
\hline Order Quantity & & Reorder Point & & \multicolumn{2}{l}{ Safety Factor } & Total Cost \\
\hline $\mathrm{Q}_{11}$ & 155 & $\mathrm{R}_{11}$ & 4 & $\mathrm{k}_{11}$ & 1.517 & $\$ 6,030$ \\
$\mathrm{Q}_{12}$ & 250 & $\mathrm{R}_{12}$ & 154 & $\mathrm{k}_{12}$ & 2.117 & \\
\hline
\end{tabular}




\begin{tabular}{lllrll}
\hline $\mathrm{Q}_{21}$ & 238 & $\mathrm{R}_{21}$ & 3 & $\mathrm{k}_{21}$ & 1.494 \\
$\mathrm{Q}_{22}$ & 340 & $\mathrm{R}_{22}$ & 124 & $\mathrm{k}_{22}$ & 1.979 \\
\hline
\end{tabular}

To observe the effect of warehouse space, Example 5 illustrates the optimal inventory policy for the situation with normal distribution demand and deterministic lead time with warehouse capacity constraint. Table 5 presents the obtained results.

Table 5. Results for Example 5 with normal distribution and space constraint

\begin{tabular}{lllll}
\hline$\theta$ & $J$ & $Q_{j}$ & $R_{j}$ & $g(\theta)$ \\
\hline 0.5 & 1 & 43 & 13 & \\
0.5 & 2 & 879 & 472 & -310 \\
\hline
\end{tabular}

As we can observe in Table 5, the order quantity for Stage 2 is in batches of 879 items and an order is placed when the inventory position drops to 472 units. Stage 2 replenishes Stage 1 in batches of 43 units each time area one inventory level drops to 13 units. The order size and the reorder point decrease until the warehouse space constraint is not active.

\section{Online and offline demands with different distributions}

In some scenarios, the demands of the two stages do not follow the same distribution. Examples 6 and 7 are provided to observe the solutions under the situation with different demand distributions. Example 6 assumes that the demands of Stage 1 and Stage 2 follow the uniform distribution and normal distribution respectively, while Example 7 shows the opposite case. Table 6 and Table 7 present the parameters and the inventory policies for Examples 6 and 7 respectively. This demonstrates the flexibility of our model to capture the demand nature in the dual-channel supply chain.

Figure 3 illustrates the effect of different switch rates of the offline demand to the online demand on the online inventory policy, for the normal independent demand and deterministic lead time without space constraint. This scenario usually occurs when a certain percentage of customers switch from the physical store shopping to the online. As shown, the higher the switch rate, the higher is the order size and the reorder point. When more customers switch from offline to online shopping, the online demands increase. To reduce ordering cost, the order size increases if the warehouse has enough space. The reorder point increases because the DDLT also increases a little. The effect on order size is higher than that on the reorder point. 
Table 6. Parameters and results for Example 6 with different demand distributions

\begin{tabular}{|c|c|c|c|c|c|c|c|}
\hline \multicolumn{4}{|c|}{ Input parameters } & \multicolumn{4}{|c|}{ Results $(\mathrm{Q}, \mathrm{R})$} \\
\hline$D_{11}$ & 3000 & $U_{21}$ & 10 & $R_{11}$ & 131 & $Q_{11}$ & 335 \\
\hline$D_{21}$ & 1200 & $U_{31}$ & 28 & $R_{21}$ & 51 & $Q_{21}$ & 142 \\
\hline$D_{31}$ & 4500 & $\mu_{12}$ & 2000 & $R_{31}$ & 198 & $Q_{31}$ & 350 \\
\hline$D_{12}$ & 24000 & $\mu_{22}$ & 1200 & $R_{12}$ & 790 & $Q_{12}$ & 2125 \\
\hline$D_{22}$ & 9600 & $\mu_{32}$ & 3500 & $R_{22}$ & 645 & $Q_{22}$ & 1756 \\
\hline$D_{32}$ & 45000 & $\sigma_{12}$ & 150 & & & $Q_{32}$ & 3660 \\
\hline$U_{11}$ & 25 & $\sigma_{22}$ & 110 & & & Total Cost & $\$ 5,315$ \\
\hline & & $\sigma_{32}$ & 165 & & & & \\
\hline
\end{tabular}

Table 7. Parameters and results for Example 7 with different demand distributions

\begin{tabular}{|c|c|c|c|c|c|c|c|}
\hline \multicolumn{4}{|c|}{ Input parameters } & \multicolumn{4}{|c|}{ Results $(Q, R)$} \\
\hline$D_{11}$ & 3500 & $\mu_{21}$ & 100 & $R_{11}$ & 340 & $Q_{11}$ & 360 \\
\hline$D_{21}$ & 1400 & $\mu_{31}$ & 320 & $R_{21}$ & 145 & $Q_{21}$ & 162 \\
\hline$D_{31}$ & 5000 & $U_{12}$ & 2000 & $R_{31}$ & 470 & $Q_{31}$ & 395 \\
\hline$D_{12}$ & 24500 & $U_{22}$ & 1200 & $R_{12}$ & 880 & $Q_{12}$ & 2300 \\
\hline$D_{22}$ & 10000 & $U_{32}$ & 3500 & $R_{22}$ & 665 & $Q_{22}$ & 1955 \\
\hline$D_{32}$ & 47000 & $\sigma_{11}$ & 20 & & & $Q_{32}$ & 3690 \\
\hline$\mu_{11}$ & 250 & $\sigma_{21}$ & 12 & & & Total Cost & $\$ 6,015$ \\
\hline$S$ & 2400 & $\sigma_{31}$ & 67 & & & & \\
\hline
\end{tabular}




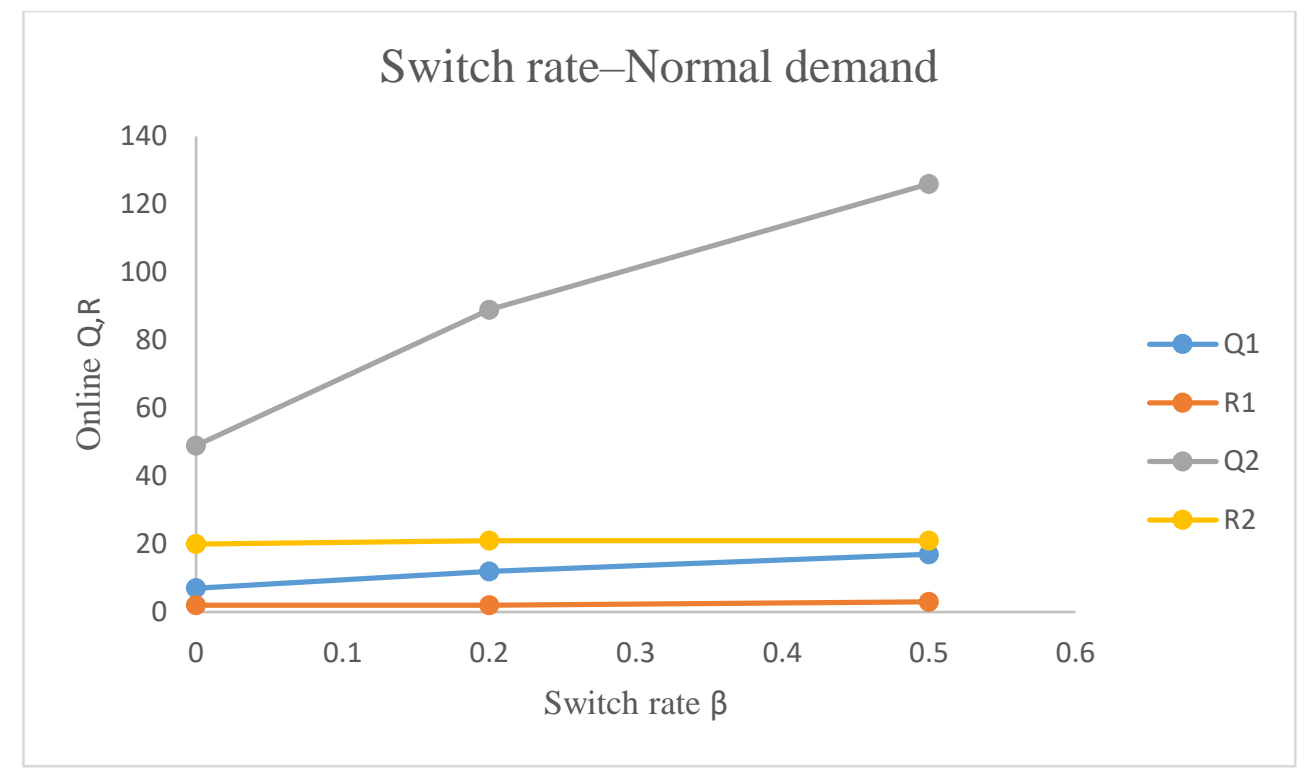

Figure 3. Inventory policy as a function of the switch rate

We perform a sensitivity analysis on the demand, mean of the DDLT, and standard deviation of the DDLT for different switch rates $(0,0.2$, and 0.5$)$. The results for 17 scenarios are listed in Table 8.

Table 8. Effect of switch rates on optimal inventory policies

\begin{tabular}{lcccccccccccc}
\hline & $\beta=0$ & \multicolumn{1}{c}{$\beta=0.2$} & \multicolumn{1}{c}{$\beta=0.5$} \\
\hline$D$ & $Q_{1}$ & $R_{1}$ & $Q_{2}$ & $R_{2}$ & $Q_{1}$ & $R_{l}$ & $Q_{2}$ & $R_{2}$ & $Q_{1}$ & $R_{1}$ & $Q_{2}$ & $R_{2}$ \\
$D+10 \%$ & 7 & 2 & 49 & 20 & 12 & 2 & 89 & 21 & 17 & 3 & 126 & 21 \\
$D+20 \%$ & 7 & 2 & 54 & 20 & 13 & 2 & 91 & 21 & 18 & 3 & 128 & 21 \\
$D+30 \%$ & 8 & 2 & 56 & 20 & 13 & 2 & 92 & 21 & 18 & 3 & 129 & 21 \\
$D-10 \%$ & 6 & 2 & 47 & 19 & 12 & 2 & 87 & 21 & 17 & 3 & 125 & 21 \\
$D-20 \%$ & 6 & 2 & 44 & 19 & 12 & 2 & 86 & 21 & 17 & 3 & 125 & 21 \\
$D-30 \%$ & 6 & 2 & 42 & 19 & 12 & 2 & 85 & 21 & 17 & 3 & 124 & 21 \\
$\mu+10 \%$ & 7 & 2 & 49 & 21 & 12 & 3 & 89 & 22 & 17 & 3 & 126 & 23 \\
$\mu+20 \%$ & 7 & 3 & 49 & 22 & 12 & 3 & 89 & 24 & 17 & 3 & 127 & 24 \\
$\mu+30 \%$ & 7 & 3 & 49 & 24 & 12 & 3 & 89 & 25 & 17 & 3 & 126 & 26 \\
$\mu-10 \%$ & 7 & 2 & 49 & 18 & 12 & 2 & 89 & 19 & 17 & 2 & 126 & 20 \\
$\mu-20 \%$ & 7 & 2 & 49 & 17 & 12 & 2 & 89 & 18 & 17 & 2 & 126 & 19 \\
$\mu-30 \%$ & 7 & 2 & 49 & 15 & 12 & 2 & 89 & 17 & 17 & 2 & 126 & 17
\end{tabular}




\begin{tabular}{lllllllllllll}
$\sigma+20 \%$ & 7 & 2 & 50 & 20 & 12 & 3 & 89 & 22 & 17 & 3 & 127 & 23 \\
$\sigma-20 \%$ & 7 & 2 & 49 & 18 & 12 & 2 & 88 & 19 & 17 & 2 & 126 & 20 \\
All $+20 \%$ & 7 & 3 & 50 & 23 & 12 & 3 & 89 & 25 & 17 & 3 & 127 & 26 \\
All $-20 \%$ & 7 & 2 & 49 & 16 & 12 & 2 & 88 & 17 & 17 & 2 & 126 & 17 \\
\hline
\end{tabular}

As indicated in Table 8, the order sizes increase when switch rates increase for all scenarios, and the reorder points increase for most situations, which means that the result is robust. Moreover, Table 8 indicates that the total expected demand has a major effect on the order size. As the total expected demand increases, the order size logically increases as well.

\subsection{Results for correlated demand}

In this section, we illustrate the solution for the correlated demand model with normal demand. Figure 6 shows the solution of the model with different split factors $(\varphi)$. As we can observed, as the split factor increases, the online demand increases and the offline demand decreases, and consequently the order sizes and the reorder point of Stage 1 are increasing as well. The changes in the online demand affect the offline demand considerably compared to that of the independent demand model.

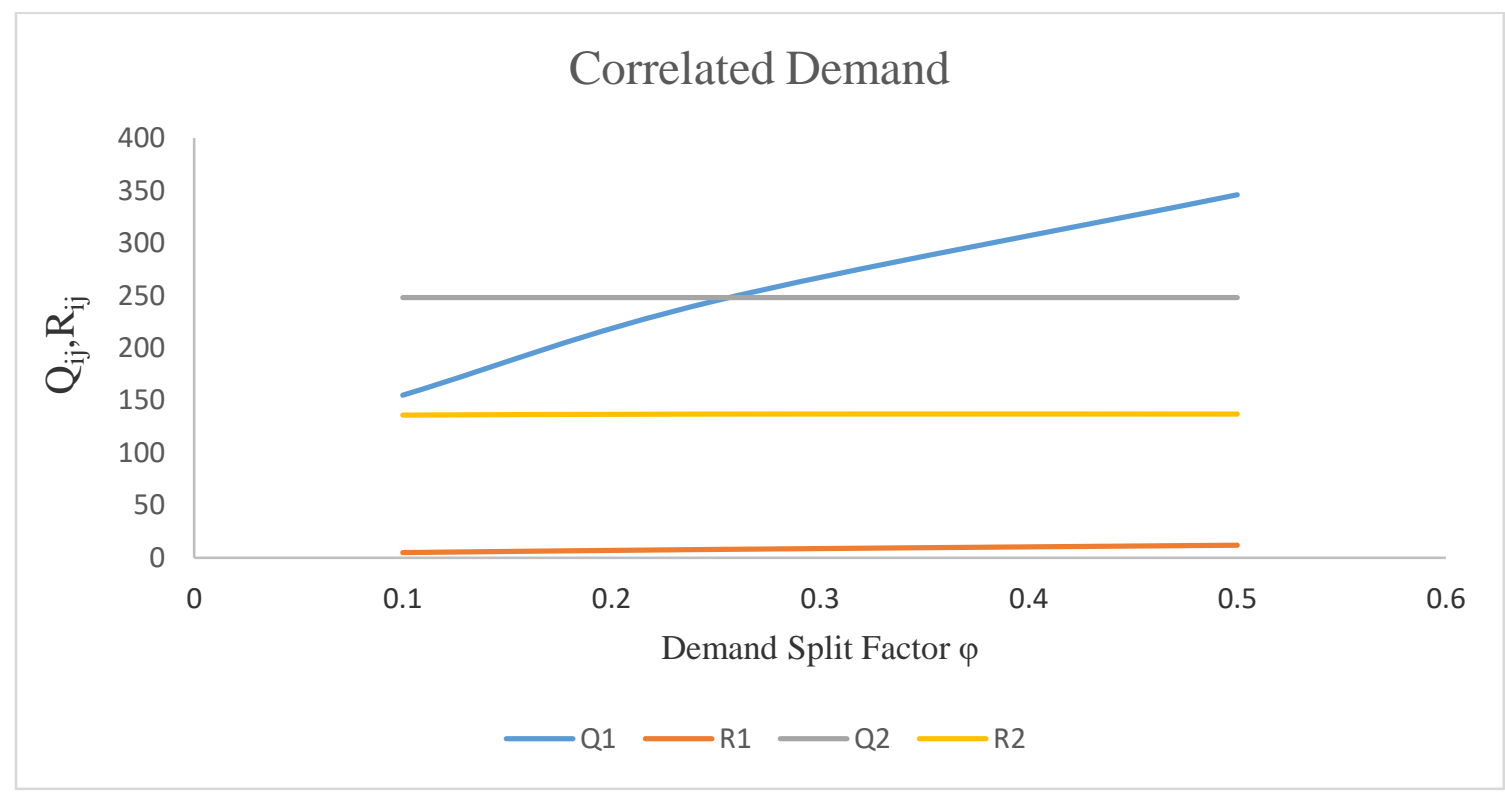

Figure 4. Effect of the demand split factor on inventory policy.

Furthermore, as shown in Figure 4, the split factor has more effect on the order size than on the reorder point. The order size is linearly increased as the split factor increases while the reorder 
point is almost unaffected. This demonstrates the flexibility of the proposed model and how it can be used as a support tool for independent and correlated demands.

\subsection{Sensitivity analysis and model robustness}

To demonstrate the robustness of the proposed solutions, we perform a numerical analysis involving the main model parameters including the demand (total expected demand, and the mean of DDLT), backorder cost, and available warehouse space. We solve the base problem and the scenarios when each input parameter is increased or decreased by $10 \%$. The obtained solution of the base model and the solution of all scenarios are presented in Table 9.

Based on the results given in Table 9, we can calculate the relative changes in the solution making different changes to the model parameters: increasing the expected annual demand by $20 \%$ would increase the order sizes, reorder points, and total cost by an average of $5.7 \%, 4.0 \%$, and 9.9\% respectively. The order sizes and reorder points would increase by an average of $9.7 \%$ and $7.70 \%$, respectively should the average DDLT increase by $20 \%$, while the total cost does not change.

Table 9 Effect of model parameters on the optimal solutions

\begin{tabular}{lccccccccc}
\hline Scenario & $R_{11}$ & $R_{12}$ & $R_{21}$ & $R_{22}$ & $Q_{11}$ & $Q_{12}$ & $Q_{21}$ & $Q_{22}$ & $T C$ \\
\hline$D$ & 6 & 17 & 8 & 21 & 96 & 114 & 191 & 203 & $\$ 3,686$ \\
$D+10 \%$ & 6 & 18 & 8 & 22 & 96 & 114 & 200 & 213 & $\$ 3,855$ \\
$D-10 \%$ & 6 & 17 & 8 & 20 & 95 & 113 & 181 & 193 & $\$ 3,508$ \\
$\mu+10 \%$ & 7 & 17 & 8 & 21 & 104 & 124 & 191 & 203 & $\$ 3,686$ \\
$\mu-10 \%$ & 6 & 17 & 7 & 21 & 87 & 104 & 191 & 203 & $\$ 3,686$ \\
$b+10 \%$ & 6 & 17 & 8 & 21 & 96 & 114 & 191 & 203 & $\$ 3,693$ \\
$b-10 \%$ & 6 & 17 & 8 & 21 & 95 & 113 & 191 & 203 & $\$ 3,677$ \\
$S-10 \%$ & 5 & 16 & 7 & 19 & 94 & 112 & 189 & 201 & $\$ 3,687$ \\
$S-20 \%$ & 4 & 12 & 6 & 14 & 92 & 110 & 182 & 193 & $\$ 3,708$ \\
\hline
\end{tabular}


Because the space constraint for the base case is not active, we observe the effect of space by decreasing the space by $10 \%$ and $20 \%$ to make the constraint active. Increasing the space by $10 \%$ (from $-20 \%$ to $-10 \%$ ) would increase the order sizes and reorder points by an average of $3.0 \%$ and $27.7 \%$ respectively. It is interesting to note that the warehouse space has a significant effect on the reorder point. This is because the system will reduce the safety inventory if it encounters a space issue.

\subsection{Cost comparison between dual-channel warehouse and decentralized warehouse}

This experiment demonstrates how the proposed model is used as a decision support tool when deciding whether to have two decentralized warehouses or one dual-channel warehouse when adding a new sales channel. A company with an offline channel typically investigates the possibility of adding an online channel when considering expanding to a dual-channel business, or vice versa. Note that for an online channel only, the warehouse usually needs to be divided into two areas: deep storage area and front picking area $(\mathrm{Xu}, 2005)$. However, for an offline channel only, the warehouse is not divided, but instead, the entire warehouse is used as a deep storage area as retailer orders are sent in pallets; hence, a small picking area is not required.

Figure 5 shows the total operating costs for a decentralized warehouse system with two single warehouses (one for online fulfillment and the other for the offline channel) and the cost of the dual-channel warehouse for different demands. For a single online channel only, the warehouse is segregated into high- and low-density areas. There are ordering costs from area one to area two and ordering costs from area two to an external supplier. There are backorder costs for area one and area two in addition to holding costs. Moreover, for a single offline channel only, the warehouse would not be divided into two areas. The total cost comprises ordering costs from an external supplier, holding costs, and backorder costs. Finally, the dual-channel warehouse is a centralized warehouse fulfilling the demand of both channels. In conclusion, the cost of operating the dual-channel warehouse is significantly lower than the cost of operating an online channel or an offline channel separately, which means that the dual-channel warehouse is cost effective. 


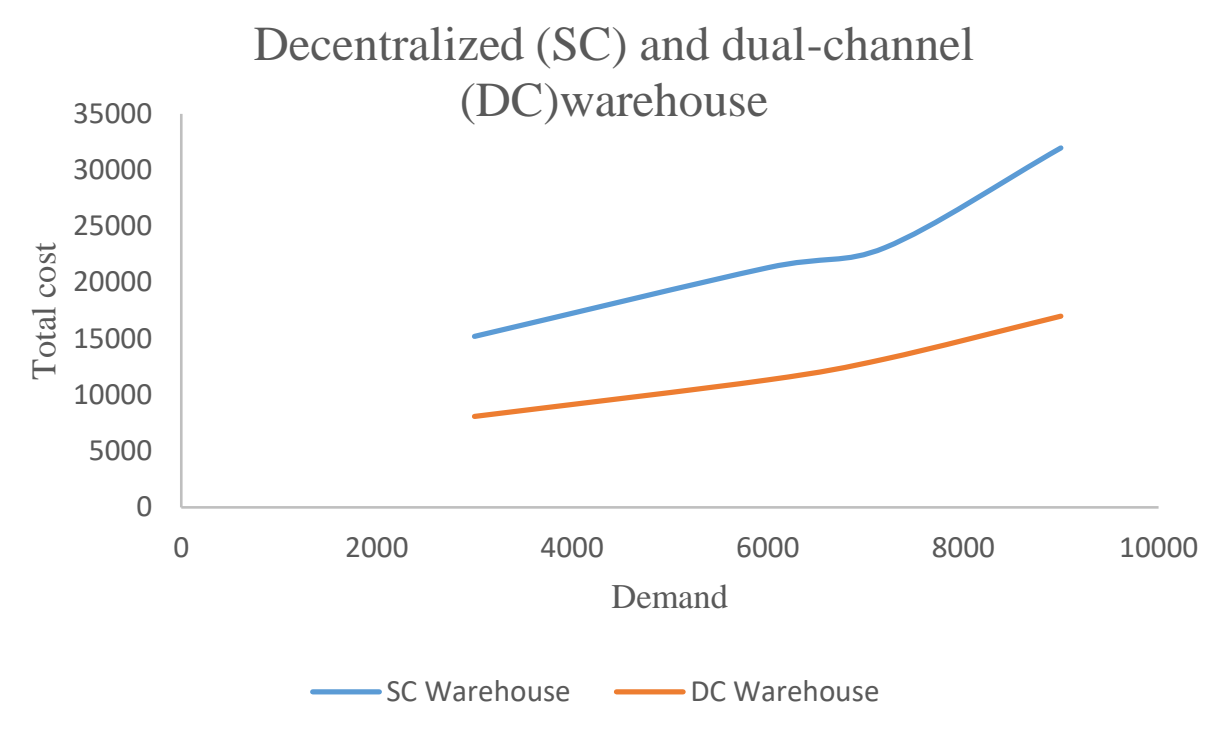

Figure 5. Cost comparison of decentralized and dual-channel warehouse with different demands

\subsection{Sales channel decision insights}

One of the major decisions faced by a management team of the dual-channel business is to decide what items to sell offline, online, or in both channels and to analyze the effect of online and offline sales on the cost. The proposed model is a useful decision support tool with regard to calculating the incurred inventory related cost in such a dilemma. Table 10 presents the results obtained for an item with different offline demand increments for three scenarios of online demand, namely unchanged, increased, and decreased, owing to the addition of the offline demand. We can observe that with a 200-unit offline demand, the cost of the system is increased from $\$ 4,208$ to $\$ 4,915$, which is approximately $\$ 3.5$ per unit of additional demand in the case where the online demand is unchanged, and $\$ 3.3$ per unit if the online demand decreases when the item is also offered offline. If the offline demand is 600 units, the total cost of the system is increased to $\$ 5,425$, which is approximately $\$ 2$ per unit of additional demand. Based on the cost increment, decision makers can make an informed decision on which channel to offer the items. The obtained results support the idea that low-demand items should be sold online while fast-moving items should be sold both online and offline.

Table 10. Cost and inventory policy with different sales channel demands

\begin{tabular}{llllllll}
\hline Input parameters & & & \multicolumn{3}{l}{ Results $(Q, R)$} \\
\cline { 5 - 7 } & & & $Q_{1}$ & $Q_{2}$ & $R_{1}$ & $R_{2}$ & Total Cost \\
\hline Online demand & Offline demand & & & &
\end{tabular}




\begin{tabular}{lllllll}
\hline 1200 & 0 & 96 & 174 & 12 & 12 & $\$ 4,208$ \\
1200 & 200 & 96 & 190 & 12 & 34 & $\$ 4,915$ \\
1200 & 400 & 96 & 204 & 12 & 34 & $\$ 5,178$ \\
1200 & 600 & 96 & 216 & 12 & 35 & $\$ 5,425$ \\
1100 & 200 & 88 & 195 & 11 & 32 & $\$ 4,881$ \\
1100 & 400 & 88 & 202 & 11 & 33 & $\$ 5,022$ \\
1300 & 200 & 89 & 202 & 11.5 & 33 & $\$ 5,022$ \\
1300 & 400 & 105 & 215 & 11.5 & 35 & $\$ 5,328$ \\
1300 & 600 & 105 & 220 & 14 & 36 & $\$ 5,549$ \\
\hline
\end{tabular}

\subsection{Channel preference and backorder cost}

In some cases, owing to the business nature, we need to decide on channel preference in terms of which channel will be prioritized to fulfill the demand. Channel preference can be easily incorporated into our model by modifying the backorder cost. Figure 6 illustrates an example of backorder cost and its effect on the channel preference.

As we can observe in Figure 6, we keep the backorder cost constant for the offline channel and increase the backorder cost for the online channel. The offline fill rate decreases and the online fill rate increases as the online backorder cost increases. The higher the online backorder cost is, the higher the online service level will be. One of the interesting findings is that the fill rate of the offline channel keeps decreasing although the fill rate of the online channel reaches almost $99 \%$. This is because the backorder cost affects the fill rate directly. As the online backorder cost increases, the optimal solution will tend to minimize the expected shortages and consequently increases the fill rate by keeping a higher level of safety stock in the online fulfillment area, which increases the possibility of stock out in Stage 2. 


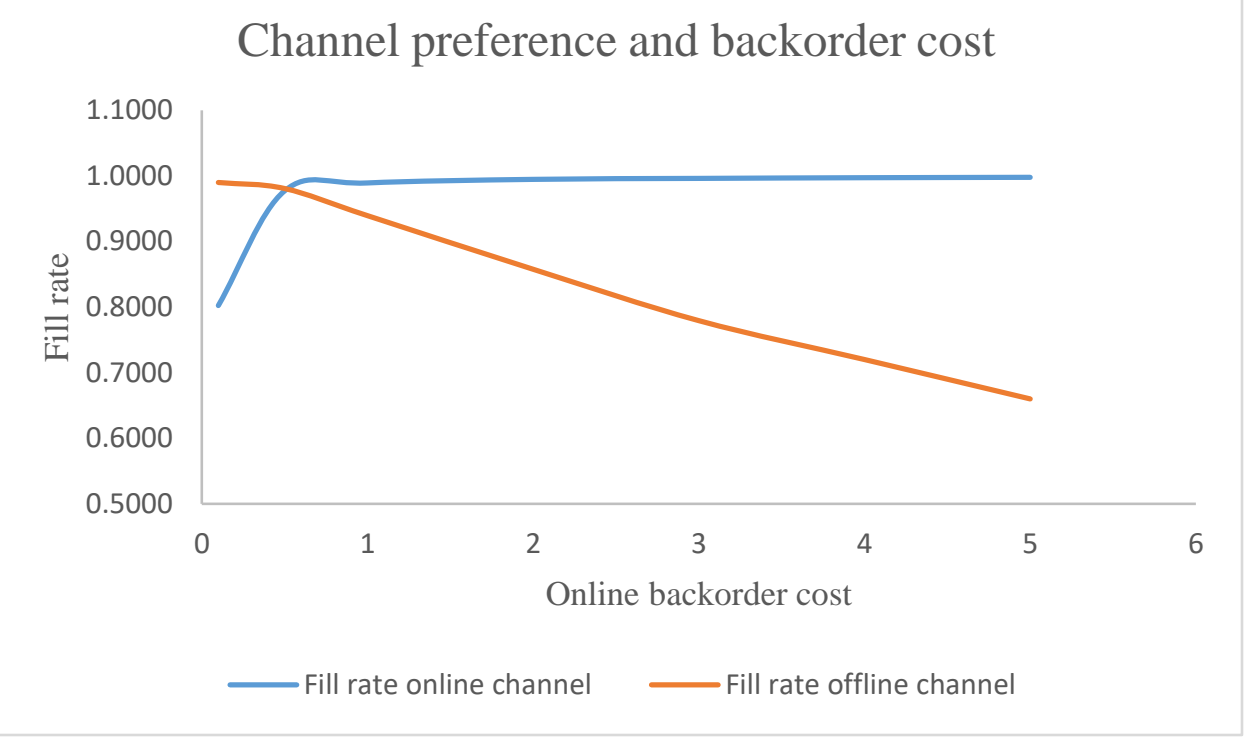

Figure 6. Backorder cost and channel preference

\subsection{Dual-channel warehouse space effects}

This section highlights the importance of having an appropriate warehouse space assigned to both offline and online areas and demonstrates how the proposed model can be used as a support tool for analyzing the effect of space and the effectiveness of the proposed warehouse management. The model has been run for two different cases: one case considers total warehouse space as a constraint, while the other case considers individual warehouse space constraint per area.

Table 11 presents the obtained results when a total warehouse space of $S=1000 \mathrm{~m}^{2}$ is considered. The total system cost is $\$ 3,693.00$. The corresponding order quantities and reorder points for the online and offline warehouse areas are within a safety factor of approximately 1.35. If the warehouse space constraint is considered individually per area and the online fulfillment area is limited to $300 \mathrm{~m}^{2}$, the cost of the system is increased to $\$ 3,739.00$, as indicated in Table 12 . The safety factor for the offline area remained the same, while the safety factor for the online area decreased to approximately 1.28 owing to the space limitation.

Table 11. Inventory policy and cost with warehouse space constraint $\left(\mathrm{S}=1000 \mathrm{~m}^{2}\right)$

\begin{tabular}{lclllll}
\hline Order Quantity & \multicolumn{2}{l}{ Reorder Point } & Safety Factor & Total Cost \\
\hline$Q_{11}$ & 18 & $R_{11}$ & 8 & $k_{11}$ & 1.379 & $\$ 3,693.00$ \\
$Q_{12}$ & 192 & $R_{12}$ & 97 & $k_{12}$ & 1.324 & \\
$Q_{21}$ & 21 & $R_{21}$ & 6 & $k_{21}$ & 1.348 & \\
\hline
\end{tabular}




\begin{tabular}{llllll}
\hline$Q_{22}$ & 203 & $R_{22}$ & 114 & $k_{22}$ & 1.355 \\
\hline
\end{tabular}

Table 12. Inventory policy and cost with dedicated area for online fulfillment $\left(S_{1}=300 \mathrm{~m}^{2}\right)$

\begin{tabular}{lllllll}
\hline \multicolumn{2}{l}{ Order Quantity } & Reorder Point & \multicolumn{3}{l}{ Safety Factor } & Total Cost \\
\hline$Q_{11}$ & 11 & $R_{11}$ & 7.6 & $k_{11}$ & 1.296 & $\$ 3,739.00$ \\
$Q_{12}$ & 192 & $R_{12}$ & 97 & $k_{12}$ & 1.324 & \\
$Q_{21}$ & 12 & $R_{21}$ & 5.9 & $k_{21}$ & 1.267 & \\
$Q_{22}$ & 203 & $R_{22}$ & 114 & $k_{22}$ & 1.355 & \\
\hline
\end{tabular}

Table 13. Inventory policy and cost with dedicated area for online fulfillment $\left(S_{1}=500 \mathrm{~m}^{2}\right)$

\begin{tabular}{lrlllll}
\hline \multicolumn{2}{l}{ Order Quantity } & Reorder Point & \multicolumn{3}{c}{ Safety Factor } & Total Cost \\
\hline$Q_{11}$ & 18 & $R_{11}$ & 8 & $k_{11}$ & 1.379 & $\$ 3,693.00$ \\
$Q_{12}$ & 192 & $R_{12}$ & 97 & $k_{12}$ & 1.324 & \\
$Q_{21}$ & 21 & $R_{21}$ & 6 & $k_{21}$ & 1.348 & \\
$Q_{22}$ & 203 & $R_{22}$ & 114 & $k_{22}$ & 1.355 & \\
\hline
\end{tabular}

If the area dedicated to the online fulfillment process is increased to $500 \mathrm{~m}^{2}$, the results are given in Table 13. The results demonstrate that the system cost is decreased to $\$ 3,693.00$. The safety factors are increased to their original values (rounding the value to 1.35) owing to the optimal dedicated warehouse space for the online fulfillment process. A $1.23 \%$ cost decrease is obtained by setting a suitable space for the online fulfillment process. 


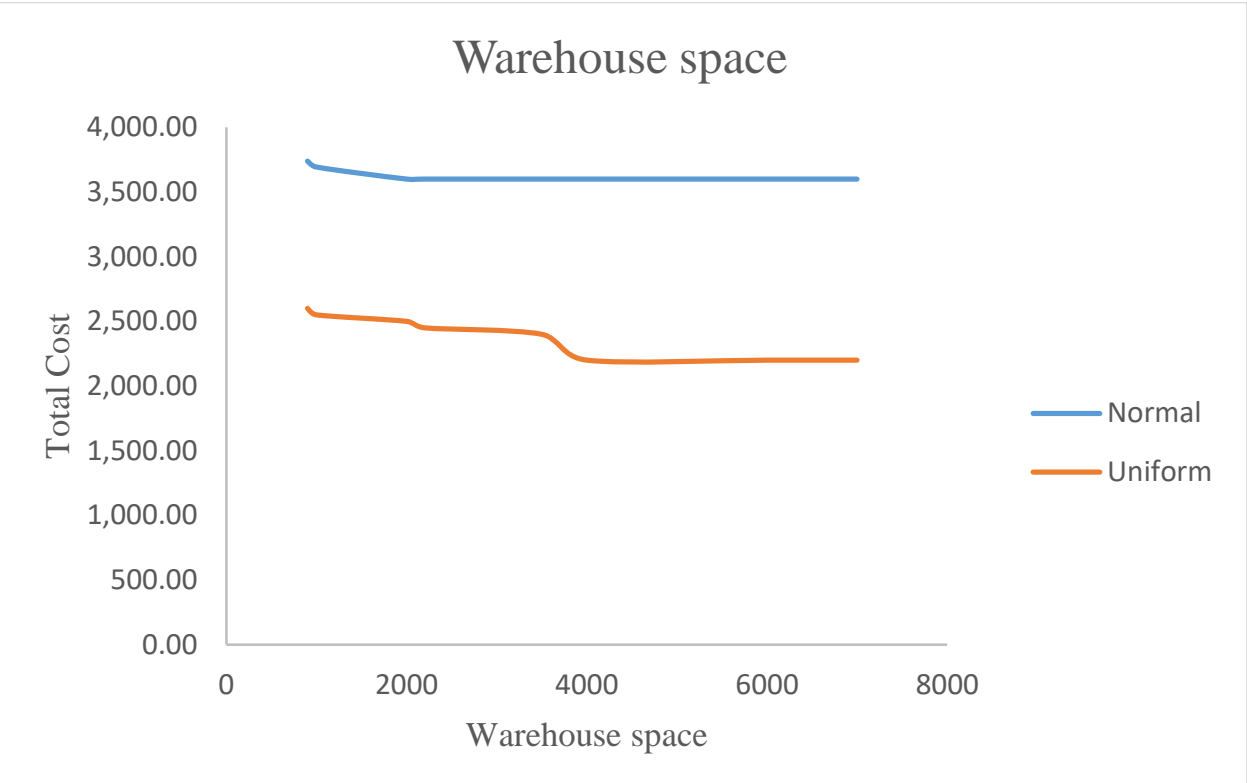

Figure 7. Total cost as a function of warehouse space

Figure 7 illustrates a numerical example of the warehouse space constraint analysis for both normal and uniform demand distributions. We can observe that for the normal distribution case, the warehouse space constraint is inactive with a warehouse space greater than $2000 \mathrm{~m}^{2}$, while for the uniform demand distribution example, the warehouse space limit is approximately $4000 \mathrm{~m}^{2}$. The analysis provides insights regarding the warehouse space and effects on the system total cost. Thus, the firm can adjust the space of the areas of the two stages when the demands or operation costs change to increase the flexibility of the dual-channel warehouse.

\subsection{Effects of demand uncertainty}

To observe the effect of demand uncertainty on the total system cost, problems with different levels of demand uncertainty are solved, for both uniform and normal distribution cases. As we can observe in Figure 8, the total cost increases when the demand variation increases owing to uncertainty. In the case of normal demand distribution, an almost linear increase is observed, while in the case of uniform demand distribution, the increase becomes steep. As uncertainty levels increase, preventive measures such as an increase in safety stock are necessary, but such measures consequently increase the system cost. 


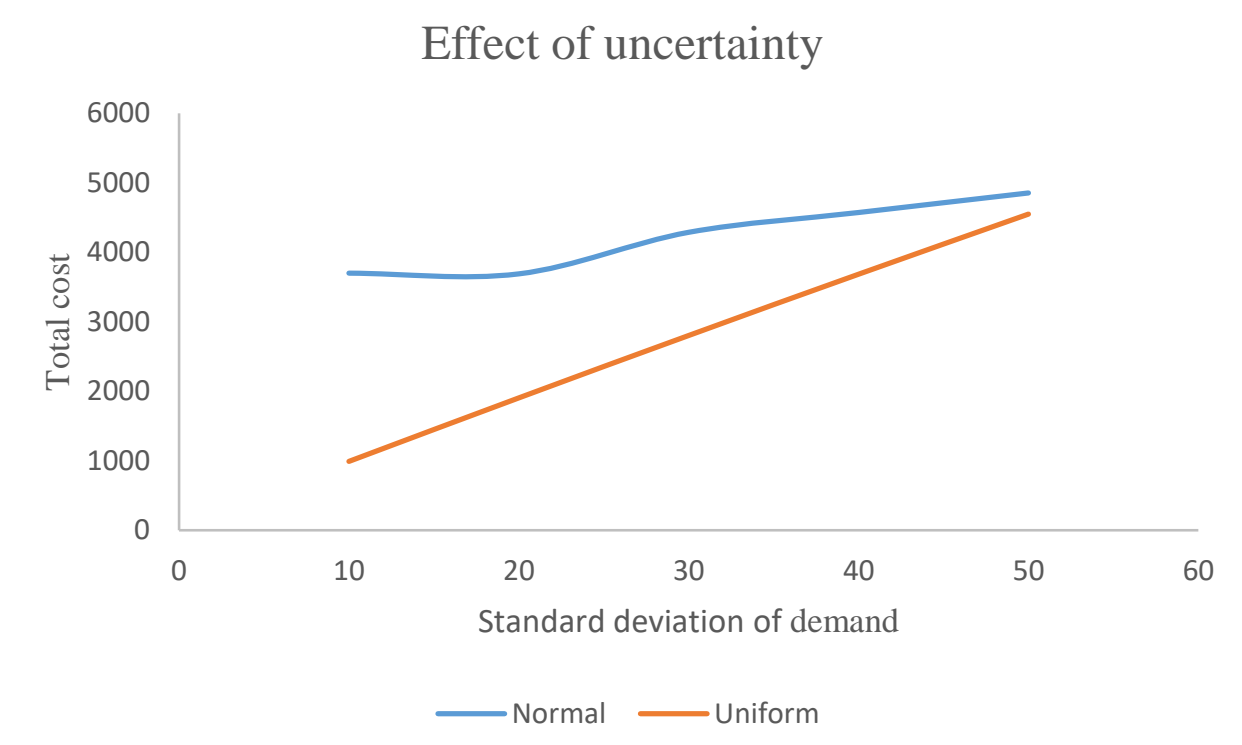

Figure 8. Effect of demand uncertainty on total cost

\section{Conclusions}

This study examines the structure of the emerging dual-channel warehouse and presents an inventory control model for the dual-channel warehouse to determine the ordering quantities and reordering points for both offline and online channels. The proposed model takes into account the warehouse structure and capacity, online fulfillment operation, ordering costs, holding costs, and backorder costs. Moreover, it considers the demand and lead time uncertainty. Closed-form solutions are developed for both uniform and normal distributions without a warehouse space constraint, and an iterative algorithm for cases with a space constraint.

Numerical examples demonstrate that the proposed model could be used to evaluate the performance of dual-channel warehouse systems. The performances of online, offline, and dualchannel warehouse strategies are also compared. Adopting the proposed inventory policy for the dual-channel warehouse inventory system considering an online sales channel alongside an offline sales channel will enhance supply chain flexibility. Moreover, it could lead to an overall reduction in ordering, inventory holding, and backorder costs. The numerical example shows that a $1.23 \%$ decrease in operational costs is obtained by allocating a suitable space for the online fulfillment process.

In addition to determining the optimal inventory policy for a dual-channel warehouse, our sensitivity analyses illustrate that the proposed model yields a robust solution and also provides a 
tool to support some strategic decisions made by companies operating in a dual-channel context. For example, it can analyze the effect of the warehouse structure and space reserved for online and offline areas on the total operating cost and service levels, and it can provide a guide or at least an option for redesigning the conventional warehouse structure to adapt to the new features of the dual-channel business.

Future research could consider investigating the warehouse layout in each stage and its effect on the total cost. Moreover, how to include the returns in designing the dual-channel warehouse as well as a sustainable and green dual-channel warehouse would be investigated. Future research can also examine the network configuration of such dual-channel warehouses so that both the responsibility and efficiency of the entire dual-channel business can be significantly improved.

\section{Acknowledgment}

The authors thank the Natural Sciences and Engineering Research Council of Canada for supporting this research with a Discovery grant (number RGPIN-2014-03594). The second author is also partially supported by the National Natural Science Foundation of China (71571010).

\section{Appendix A. Proof of Theorem 1}

$$
\begin{aligned}
C\left(Q_{i 2}, R_{i 2}, Q_{i 1},\right. & \left.R_{i 1}\right) \\
& =\sum_{i} \frac{A_{i 2} D_{i 2}}{Q_{i 2}}+\sum_{i} \frac{A_{i 1} D_{i 1}}{Q_{i 1}}+\sum_{i} h_{i 2}\left[\left(\frac{Q_{i 2}}{2}\right)+\left(R_{i 2}-\mu_{x_{i 2}}\right)\right] \\
& +\sum_{i} h_{i 1}\left[\left(\frac{Q_{i 1}}{2}\right)+\left(R_{i 1}-\mu_{x_{i 1}}\right)\right]+\sum_{i} \frac{b_{i 2} D_{i 2}}{Q_{i 2}}\left[\int_{R_{i 2}}^{\infty}\left(x_{i 2}-R_{i 2}\right) f\left(x_{i 2}\right) d x_{i 2}\right] \\
& +\sum_{i} \frac{b_{i 1} D_{i 1}}{Q_{i 1}}\left[\int_{R_{i 1}}^{\infty}\left(x_{i 1}-R_{i 1}\right) f\left(x_{i 1}\right) d x_{i 1}\right]
\end{aligned}
$$

We have

$$
\begin{aligned}
& C_{Q_{i 1} Q_{i}}=\frac{\partial^{2} C}{\partial Q_{i 1}^{2}}=\frac{2 D_{i 1}}{Q_{i 1}^{3}}\left\{A_{i 1}+b_{i 1} \int_{R_{i 1}}^{\infty}\left(x_{i 1}-R_{i 1}\right) f\left(x_{i 1}\right) d x_{i 1}\right\}>0 \\
& C_{Q_{i 1} R_{i 1}}=\frac{\partial^{2} C}{\partial Q_{i 1} \partial R_{i 1}}=\frac{D_{i 1} b_{i 1}}{Q_{i 1}^{2}}\left\{\int_{R_{i 1}}^{\infty} f\left(x_{i 1}\right) d x_{i 1}\right\}>0
\end{aligned}
$$




$$
\begin{aligned}
& C_{R_{i 1} Q_{i 1}}=\frac{\partial^{2} C}{\partial R_{i 1} \partial Q_{i 1}}=\frac{D_{i 1} b_{i 1}}{Q_{i 1}^{2}}\left\{\int_{R_{i 1}}^{\infty}\left(x_{i 1}-R_{i 1}\right) f\left(x_{i 1}\right) d x_{i 1}\right\}>0 \\
& C_{R_{i 1} R_{i 1}}=\frac{\partial^{2} C}{\partial R_{i 1}^{2}}=\frac{A_{i 1} D_{i 1}}{Q_{i 1}} f\left(R_{i 1}\right)>0 \\
& C_{Q_{i 2} Q_{i 2}}=\frac{\partial^{2} C}{\partial Q_{i 2}^{2}}=\frac{2 D_{i 2}}{Q_{i 2}^{3}}\left\{A_{i 2}+b_{i 2} \int_{R_{i 2}}^{\infty}\left(x_{i 2}-R_{i 2}\right) f\left(x_{i 2}\right) d x_{i 2}\right\}>0 \\
& C_{Q_{i 2} R_{i 2}}=\frac{\partial^{2} C}{\partial Q_{i 2} \partial R_{i 2}}=\frac{D_{i 2} b_{i 2}}{Q_{i 2}^{2}}\left\{\int_{R_{i 2}}^{\infty} f\left(x_{i 2}\right) d x_{i 2}\right\}>0 \\
& C_{R_{i 2} Q_{i 2}}=\frac{\partial^{2} C}{\partial R_{i 2} \partial Q_{i 2}}=\frac{D_{i 2} b_{i 2}}{Q_{i 2}^{2}}\left\{\int_{R_{i 2}}^{\infty}\left(x_{i 2}-R_{i 2}\right) f\left(x_{i 2}\right) d x_{i 2}\right\}>0 \\
& C_{R_{i 2} R_{i 2}}=\frac{\partial^{2} C}{\partial R_{i 2}^{2}}=\frac{A_{i 2} D_{i 2}}{Q_{i 2}} f\left(R_{i 2}\right)>0
\end{aligned}
$$

All second order derivatives are greater than 0 for all non-negative $Q_{i 1}, R_{i 1}, Q_{i 2}, R_{i 2}$. Thus, $\mathrm{C}$ is strictly convex. Furthermore, as constraints (3) and (5) are linear, the problem $(P)$ is convex.

\section{Appendix B. Input data}

B.1 Parameters for Example 1 with uniform distribution demand and deterministic lead time with space constraint

\begin{tabular}{llllll}
\hline Parameter & Value & Parameter & Value & Parameter & Value \\
\hline$i$ & 1,2 & $U_{22}$ & 800 & $h_{11}$ & 8 \\
$j$ & 1,2 & $A_{11}$ & 10 & $h_{12}$ & 1 \\
$\mathrm{D}_{11}$ & 3000 & $A_{12}$ & 125 & $h_{21}$ & 8 \\
$\mathrm{D}_{12}$ & 24000 & $A_{21}$ & 10 & $h_{22}$ & 1 \\
$\mathrm{D}_{21}$ & 1200 & $A_{22}$ & 125 & $\gamma_{11}$ & 0.2 \\
$\mathrm{D}_{22}$ & 9600 & $b_{11}$ & 10 & $\gamma_{12}$ & 1 \\
$\mathrm{U}_{11}$ & 250 & $b_{12}$ & 60 & $\gamma_{21}$ & 1 \\
$\mathrm{U}_{12}$ & 2000 & $b_{21}$ & 10 & $\gamma_{22}$ & 0.2 \\
$U_{21}$ & 100 & $b_{22}$ & 60 & $S$ & 90000 \\
\hline
\end{tabular}


B.2 Parameters for Example 3 with normal distribution demand

\begin{tabular}{llllll}
\hline Parameter & Value & Parameter & Value & Parameter & Value \\
\hline$i$ & 1,2 & $\sigma_{11}$ & 0.5 & $b_{21}$ & 0.5 \\
$j$ & 1,2 & $\sigma_{12}$ & 4 & $b_{22}$ & 8 \\
$D_{11}$ & 240 & $\sigma_{21}$ & 0.3 & $h_{11}$ & 1 \\
$D_{12}$ & 2400 & $\sigma_{22}$ & 2.9 & $h_{12}$ & 10 \\
$D_{21}$ & 350 & $A_{11}$ & 50 & $h_{21}$ & 0.5 \\
$D_{22}$ & 4500 & $A_{12}$ & 125 & $h_{22}$ & 8 \\
$\mu_{11}$ & 3 & $A_{21}$ & 40 & $\gamma_{11}$ & 2 \\
$\mu_{12}$ & 120 & $A_{22}$ & 100 & $\gamma_{12}$ & 0.2 \\
$\mu_{21}$ & 2.5 & $b_{11}$ & 10 & $\gamma_{21}$ & 1 \\
$\mu_{22}$ & 100 & $b_{12}$ & 60 & $\gamma_{22}$ & 0.1 \\
\hline
\end{tabular}

B.3 Parameters for Example 5 with normal distribution demand with space constraint

\begin{tabular}{llllll}
\hline Parameter & Value & Parameter & Value & Parameter & Value \\
\hline$i$ & 1 & $\sigma_{12}$ & 50 & $b_{11}$ & 50 \\
$j$ & 1,2 & $A_{11}$ & 40 & $b_{12}$ & 2000 \\
$D_{11}$ & 120 & $A_{12}$ & 4000 & $\gamma_{11}$ & 100 \\
$D_{12}$ & 1600 & $h_{11}$ & 20 & $\gamma_{12}$ & 50 \\
$\mu_{11}$ & 30 & $h_{12}$ & 10 & $S$ & 3500 \\
$\mu_{12}$ & 750 & $A$ & 0.99 & & \\
$\sigma_{11}$ & 10 & $z_{1-\alpha}$ & -1.3 & & \\
\hline
\end{tabular}

B.4 Input parameters for sensitivity analysis example

\begin{tabular}{llllll}
\hline Parameter & Value & Parameter & Value & Parameter & Value \\
\hline$i$ & 1,2 & $\sigma_{11}$ & 2 & $b_{21}$ & 10 \\
$j$ & 1,2 & $\sigma_{12}$ & 8.5 & $b_{22}$ & 10 \\
$D_{11}$ & 165 & $\sigma_{21}$ & 1.5 & $h_{11}$ & 8 \\
$D_{12}$ & 1650 & $\sigma_{22}$ & 10 & $h_{12}$ & 8 \\
\hline
\end{tabular}




\begin{tabular}{llllll}
\hline$D_{21}$ & 185 & $A_{11}$ & 6.5 & $h_{21}$ & 8 \\
$D_{22}$ & 1850 & $A_{12}$ & 85 & $h_{22}$ & 8 \\
$\mu_{11}$ & 5 & $A_{21}$ & 8.5 & $\gamma_{11}$ & 10 \\
$\mu_{12}$ & 85 & $A_{22}$ & 85 & $\gamma_{12}$ & 1 \\
$\mu_{21}$ & 4 & $b_{11}$ & 10 & $\gamma_{21}$ & 10 \\
$\mu_{22}$ & 100 & $b_{12}$ & 10 & $\gamma_{22}$ & 1 \\
& & & & $S$ & 1000 \\
\hline
\end{tabular}

B.5 Parameters for warehouse space comparisons example

\begin{tabular}{llllll}
\hline Parameter & Value & Parameter & Value & Parameter & Value \\
\hline$i$ & 1,2 & $\sigma_{11}$ & 2 & $b_{21}$ & 10 \\
$j$ & 1,2 & $\sigma_{12}$ & 8.5 & $b_{22}$ & 10 \\
$D_{11}$ & 165 & $\sigma_{21}$ & 1.5 & $h_{11}$ & 8 \\
$D_{12}$ & 1650 & $\sigma_{22}$ & 10 & $h_{12}$ & 8 \\
$D_{21}$ & 185 & $A_{11}$ & 6.5 & $h_{21}$ & 8 \\
$D_{22}$ & 1850 & $A_{12}$ & 85 & $h_{22}$ & 8 \\
$\mu_{11}$ & 5 & $A_{21}$ & 8.5 & $\gamma_{11}$ & 10 \\
$\mu_{12}$ & 85 & $A_{22}$ & 85 & $\gamma_{12}$ & 1 \\
$\mu_{21}$ & 4 & $b_{11}$ & 10 & $\gamma_{21}$ & 10 \\
$\mu_{22}$ & 100 & $b_{12}$ & 10 & $\gamma_{22}$ & 1 \\
\hline
\end{tabular}

\section{References}

Abdul-Jalbar B., Gutierrez, J., Sicilia J., 2006. Single cycle policies for the one-warehouse Nretailer inventory/distribution system. Omega 34, 196-208.

Agatz, N. A. H., Fleischmann, M., Nunen, J. A. E. E., 2008. E-Fulfillment and Multi-Channel Distribution - A Review. European Journal of Operational Research 187 (2), 339-356.

Allgor, R., Graves, S., Xu, P. J., 2003. Traditional Inventory Models in an E-Retailing Setting: A Two-Stage Serial System with Space Constraints. Working paper, Massachusetts Institute of Technology. 
Alptekinoglu A., Tang, C. S., 2005. A model for analyzing multi-channel distribution systems. European Journal of Operational Research 163, 802-24.

Bartholdi, J. J., Hackman, S. T., 2008. Allocating space in a forward pick area of a distribution center for small parts. IIE Transactions 40, 1046-1053.

Bendoly, E., 2004. Integrated inventory pooling for firms servicing both online and store demand. Computers \& Operations Research 31, 1465-1480.

Bichescu B. C., Fry, M. J., 2009. A numerical analysis of supply chain performance under split decision rights. Omega 37 (2009), 358 - 379.

Boyaci, T., 2005. Competitive stocking and coordination in a multiple-channel distribution system. Journal HE transactions 37 (5), 407-427.

Chen, B., Chen, J., 2017. When to introduce an online channel, and offer money back guarantees and personalized pricing?. European Journal of Operational Research 257, 614-624.

Chiang, W. K., Monahan, G. E., 2005. Managing inventories in a two-echelon dual-channel supply chain. European Journal of Operational Research 162 (2), 325-341.

Das, R., Hanaoka, S., 2014. Relief inventory modelling with stochastic lead-time and demand. European Journal of Operational Research 235, 616-623.

De Bodt, M. A., Graves, S. C., 1985. Continuous review policies for inventory problem with stochastic demand. Management Science 31 (10), 1286-1299.

De Koster, R., 2003. Distribution strategies for online retailers. IEEE Transactions on Engineering Management 50 (4), 448-457.

Fattahi, P., Hajipour, V., Nobari, A., 2015. A bi-objective continuous review inventory control model: Pareto-based meta-heuristic algorithms. Applied Soft Computing 32, 211-223.

Graves J. B., 2012. Maximizing Productivity in E-commerce 3PLs, Inbound Logistics, 3PL, Americas.

Geng, Q., Mallik, S., 2007. Inventory competition and allocation in a multi-channel distribution system. European Journal of Operational Research 182 (6), 704-729.

Ghalebsaz-Jeddi, B., Shultes, B. C., Haji, R., 2004. A Multi-product continuous review inventory system with stochastic demand, backorders, and a budget constraint. European Journal of Operational Research 158 (2), 456-469. 
Giri, B. C., Chakraborty, A., Maiti, T., 2017. Pricing and return product collection decisions in a closed- loop supply chain with dual-channel in both forward and reverse logistics. Journal of Manufacturing Systems 42 (2017), 104-123.

Gunasekaran, A., Subramanian, N., Papadopoulos, T., 2017. Information technology for competitive advantage within logistics and supply chains: a review. Transportation Research Part E 99 (2017), $14-33$.

Hadley, G., Whitin, T. M., 1963. Analysis of Inventory Systems. Englewood Cliffs, New Jersey: Prentice Hall.

Hackman, S. T., Rosenblatt, M. J.,1990. Allocating items to an automated storage and retrieval system. IIE Transactions, 22, 1,7-14.

Hoseininia M, Seyyed, E. M. M., Didehvar, F., Haghib, A., 2013. Inventory competition in a multichannel distribution system: the Nash and Stackelberge Game. Industrial Engineering 20 (3), $846-854$.

Hua, Z., Li, S., 2008. Impacts of demand uncertainty on retailer's dominance and manufacturerretailer supply chain cooperation. Omega 36 (2008), 697-714.

Huang, S., Yang, C., Zhang, X., 2012. Pricing and production decisions in dual-channel supply chains with demand disruptions. Computers \& Industrial Engineering 62, 70-83.

Hübner, A., Kuhn, H., Wollenburg, J., 2016. Last mile fulfilment and distribution in omni-channel grocery retailing A strategic planning framework. International Journal of Retail \& Distribution Management 44 (3), 228-247.

Hübner, A., Holzapfel, A., Kuhn, H., 2015. Operations management in multi-channel retailing: an expletory study. Operations Management Research 8 (3), 84-100.

Khouja, M. 2003. Optimizing inventory decisions in a multi-stage multi-customer supply chain. Transportation Research Part E 39 (2003), 193-208.

Khouja, M., Stylianou, A. C., 2009. A (Q,R) Inventory model with a drop shipping option For ebusiness. Omega 37 (2009), 896-908.

Kilcourse, B., Rowen, S.,2008. Finding the integrated multi-channel retailer. Miami: Retail Systems Research.

Kundu, A., Chakrabarti, T., 2012. A multi-product continuous review inventory system in stochastic environment with budget constraint. Optimization Letters 6 (2), 299-313. 
Lee, W. 2005. A joint economic lot size model for raw material ordering, manufacturing setup, and finished goods delivering. Omega 33, 163-74.

Li, T., Zhao, X., Xie, J., 2015. Inventory management for dual sales channels with inventory-leveldependent demand. Journal of the Operational Research Society (2015) 66, 488-499.

Lin, Z., 2016. Price promotion with reference price effects in supply chain. Transportation Research Part E 85 (2016), 52-68.

Lippman, S., McCardle, K., 2004. The competitive newsboy. Operations Research 45, 54-65.

Liu, M., Cao, E., Salifou, C. K., 2016. Pricing strategies of a dual-channel supply chain with risk aversion. Transportation Research Part E 90 (2016), 108-120

Lu, Q., Liu, N., 2015. Effects of e-commerce channel entry in a two-echelon supply chain: a comparative analysis of single- and dual-channel distribution systems. International Journal of Production Economics 165 (1),100-111.

Mahar, S., Bretthauer, K. M., Venkataramananb, M. A., 2009. An algorithm for solving the multiperiod online fulfillment assignment problem. Mathematical and Computer Modelling 50 (9), 1294-1304.

Master, N., 2015. Warehouse Management Solutions for Multi-Channel Retail Challenges, RFgen, http://www.rfgen.com/blog/warehouse-management-solutions-for-multi-channel-retailchallenges.

Matsui, K., 2017. When should a manufacturer set its direct price and wholesale price in dualchannel supply chains. European Journal of Operational Research 258 (2017), 501-511.

Matsui, K., 2016. Asymmetric product distribution between symmetric manufacturers using dualchannel supply chains. European Journal of Operational Research 248 (2), 646-657.

McCrea, B.,2017. 7 Warehouse e-commerce best practices for 2017. Modern Materials Handling, Warehousing Management Edition; Framingham 72.1 (Jan 2017): 42-44, 46-47.

Nahmias, S., 2013. Production and Operations Analysis. $6^{\text {Th }}$ edition. McGraw-Hill/Irwin Series Operations and Decision Sciences.

Panda, S., Modak, N. M., Sana, S. S., Basu, M., 2015. Pricing and replenishment policies in dualchannel supply chain under continuous unit cost decrease. Applied Mathematics and Computation 256 (2015), 913-929.

Rodríguez, B., Aydin, G., 2015. Pricing and assortment decisions for a manufacturer selling through dual-channels. European Journal of Operational Research 242, 901-909. 
Ryan, J. K., Sun, D., Zhao, X., 2013. Coordinating a supply chain with a manufacturer-owned online channel: A dual-channel Model under Price Competition. IEEE Transactions on Engineering Management 60 (2), 247-259.

Sarkara, B., Mandalb, B., Sarkarb, S., 2015. Quality improvement and backorder price discount under controllable lead time in an inventory model. Journal of Manufacturing Systems 35 (2015), 26-36.

Schneider, F, Klabjan, D., 2013. Inventory control in multi-channel retail. European Journal of Operational Research 227(1),101-111.

Seifert, R. W., Thoneman, U. W., Sieke, M. A., 2006. Relaxing channel separation-integrating a virtual store into the supply chain. IIE Transactions 38, 917-31.

Silver, E., Peterson, R., 1985. Decision Systems for Inventory Management and Production Planning. Wiley, New York.

Swaminathan, J. M., Tayur, S. R., 2003. Models for supply chains in e-business. Management Science 49 (10), 1387-1406.

Takahashi, K., Aoi, Hirotani, T. D., Morikawa, K., 2011. Inventory control in a two-echelon dualchannel supply chain with setup of production and delivery. International Journal of Production Economics 133 (1), 403-415.

Teimoury, E., Mirzahosseinian, H., Kaboli, A., 2008. A mathematical method for managing inventories in a dual-channel supply chain. International Journal of Industrial Engineering \& Production Research 19 (4), 31-37.

Tetteh, A., Xu, Q., 2014. Supply chain distribution networks: single-, dual-, \& omni-channel. Interdisciplinary Journal of Research in Business 3 (9), 63-73.

U.S. Department of Commerce. Accessed on August $04 \quad 2016$. https://www.census.gov/retail/mrts/www/data/pdf/ec_current.pdf

Tsay, A., Agrawal, N., 2004. Channel conflict and coordination in the e-commerce age. Production and Operations Management 13, 93-110.

Wang, Y., Li, G., Cheng, T. C. E., 2016. Channel selection in a supply chain with a multi-channel retailer: the role of channel operating costs. International Journal of Production Economics 173 (1), 54-65.

Wanke, P. F., 2008. The uniform distribution as a first practical approach to new product inventory management. International Journal of Production Economics 114 (2008), 811-819. 
Wu, S., 2015. Forrester Research Online Retail Forecast, 2015 To 2020 (U.S.). www.forrester.com.

Xiao, T., Shi, J., 2016. Pricing and supply priority in a dual-channel supply chain. European Journal of Operational Research 254 (3), 813-823.

Xu, P. J., 2005. Order Fulfillment in Online Retailing: What Goes Where. Ph.D. diss., Massachusetts Institute of Technology.

Yan, B., Wang, T., Liu, Y. P., Liu, Y., 2016. Decision analysis of retailer-dominated dual-channel supply chain considering cost misreporting. International Journal of Production Economics 178 (1), 34-41.

Yano, C. A., 1985. New Algorithm For Q,R Systems With Complete Backordering Using a Fill rate Criteria. Technical Report 81. Department of Industrial Operations Engineering. The university of Michigan.

Yao, D. Q., Yue, X., Wang, X., Liu, J., 2005. The impact of information sharing on a returns policy with the addition of a direct channel. International Journal of Production Economics 97,196209.

Yao, D. Q., Liu, J. J., 2005. Competitive pricing of mixed retail and e-tail distribution channels. Omega 33 (2005), 235-247.

Yao, D. Q., Yue, X., Mukhopadhyay, S. K., Wang, Z., 2009. Strategic inventory deployment for retail and e-tail stores. Omega 37 (2009), 646-658.

Zhang, H., Tian, C., 2014. Inventory decisions of a dual-channel supply chain based on service level. 2014 International Conference on Management Science \& Engineering (21th). August 17-19, 2014 Helsinki, Finland.

Zhang, C., Tan, G-W., Robb, D. J., Zheng, X., 2006. Sharing shipment quantity information in the supply chain. Omega $34,427-38$.

Zhang, J., Farris, P. W., Irvin, J. W., Kushwaha, T., Steenburgh, T. J., Weitz, B. A., 2010. Crafting integrated multi-channel retailing strategies. Journal of Interactive Marketing 24 (2), 168-180.

Zhao F., Wu, D., Liang, L., Dolgui, A., 2016. Lateral inventory transshipment problem in onlineto-offline supply chain. International Journal of Production Research 54 (7), 1951-1963.

Zipkin, P., 1986. Inventory service-level measures: convexity and approximation. Management Science 32, 8, 975-981. 